\title{
BTS statement on malignant mesothelioma in the UK, 2007
}

\author{
British Thoracic Society Standards of Care Committee
}

Thorax 2007;62(Suppl II):ii1-ii19. doi: 10.1136/thx.2007.087619

$\mathrm{T}$ he first British Thoracic Society (BTS) statement on mesothelioma was published in 2001 by a Working Party of the Standards of Care Committee of the BTS ${ }^{1}$ in response to a request by the National Health Executive in England. In the last 5 years enough progress has been made to justify the preparation of a second statement. The most significant updates are in sections reviewing radiology and biopsy techniques and interpretation, the potential use of tumour markers, chemotherapy, radical treatment and the roles of the specialist nurse and multidisciplinary team approach in management. Recent major clinical trials are also reviewed.

As before, this updated statement was written by a Working Party of clinicians with an interest and experience in the disease with the aim of compiling a document to assist in the management of pleural and peritoneal malignant mesothelioma in the UK. We were again assisted by co-opted specialists, including radiologists, pathologists, nurses and oncologists, whose full details are given in Appendix 1. The draft was reviewed by the whole membership of the BTS and also sent to expert groups and patient representatives for whose comments we are grateful. Our statement is the result of this consultation process.

This statement is compiled primarily for clinicians who may be involved in caring for patients with mesothelioma and is based on literature searches and reviews by members of the Working Party responsible for particular sections. However, like its predecessor, it is not strictly evidence-based as we did not attempt a comprehensive review of all available literature. Moreover, in most aspects of this subject there are still no randomised trials on which to base guidelines. The management of mesothelioma remains subject to debate and variations in practice, so we have retained the term "statement" rather than "guidelines" in this revision.

This statement should be read in conjunction with the Mesothelioma Framework produced by the Department of Health's Lung Cancer and Mesothelioma Advisory Group. ${ }^{2}$ The latter document is directed mainly at Strategic Health Authorities, cancer networks, primary care trusts and NHS trusts in England, and provides advice on how to organise mesothelioma services in order to improve standards of care to a uniformly high level.

Correspondence to:

Dr John Wiggins, Wexham

Park Hospital, Slough SL2

4HL, UK; john.wiggins@

hwph-tr.nhs.uk

Received 20 July 2007

Accepted 13 August 2007 systematically recorded in the late 1960s when the mesothelioma register was established. ${ }^{3}$ Latest available projections of the future burden of the disease in Britain suggest that the annual number of deaths will peak at between 1950 and 2450 deaths per year sometime between the years 2011 and 2015. ${ }^{4}$ The model suggests that for men in the highest risk birth cohorts - that is, those born in the late 1930s or early 1940s-mesothelioma may account for around $0.7 \%$ of all deaths. Although highly uncertain, long-range predictions suggest that around 65000 deaths from mesothelioma may occur over the next 50 years. There is widespread variation in the incidence of malignant mesothelioma in England: two Strategic Health Authorities have $<30$ cases annually while two have $>100$ cases per year. ${ }^{2}$

Asbestos fibres are the cause of most cases of mesothelioma. Evidence from two British studies suggests that the proportion of men with mesothelioma directly attributable to occupational asbestos exposure may be about $85 \%,{ }^{56}$ and this is consistent with evidence from studies in other countries. $^{78}$ However, mesothelioma can also result from para-occupational exposures (for example, women who have laundered their husband's overalls) and non-industrial environmental exposures. ${ }^{6}$ Furthermore, there is some evidence to suggest that the rate of "spontaneous" mesotheliomas each year-that is, deaths which would have occurred even if the industrial exploitation of asbestos had never taken place-is around one per million or about 30 men and a similar number of women per year in Britain.

Mesothelioma can be induced by other nonasbestos fibres such as erionite found in rock in certain areas of Turkey. ${ }^{9}$ The suggestion that Simian virus 40 (SV40), ${ }^{10}$ which was found to contaminate polio vaccines administered in the 1950s and early 1960s in Great Britain, is a contributory factor has been refuted by recent studies. ${ }^{11}{ }^{12}$

The latency period between first exposure to asbestos and death from mesothelioma is typically very long. One review of over 20 epidemiological studies which documented latent periods reported a median latency of 32 years, very few cases with latency of $<20$ years and nearly one-third of cases with latency of $>40$ years. ${ }^{13}$ A more recent British study reported a mean latency of 41 years (range $15-67)$.

Abbreviations: CALGB, Cancer and Leukaemia Group B; $\mathrm{CT}$, computed tomography; EORTC, European Organisation for Research and Treatment of Cancer; EPP, extrapleural pneumonectomy; FDG, ${ }^{18}$ F-fluorodeoxyglucose; IIDB, industrial injuries disablement benefit; MARS, Mesothelioma And Radical Surgery; MRI, magnetic resonance imaging; PET, positron emission tomography; PS, performance status; RECIST, Response Evaluation Criteria in Solid Tumours; SMRP, soluble mesothelin-related proteins; SUV, standardised uptake value; VATS, video-assisted thoracic surgery 


\section{Summary of key points}

- Malignant mesothelioma will increase in incidence over the next 5-10 years. It is inexorably progressive with a very poor 5-year survival and a median survival of 814 months.

- Malignant mesothelioma should be considered in any patient with either pleural fluid or pleural thickening, especially if chest pain is present. Prompt referral to a respiratory physician for further assessment is indicated.

- Where a chest radiograph is suggestive of malignant pleural disease, a copy report should ideally be sent to a designated member of the lung cancer multidisciplinary team, usually the chest physician, and preferably electronically or by fax.

- The pathological diagnosis of a diffuse malignant mesothelioma is not always straightforward and interpretation should always be taken in context with full knowledge of the clinical history, examination findings and radiological appearance.

- Where there is diagnostic uncertainty or where radical treatment is considered, cases should be referred to a specialist multidisciplinary team.

- An appropriately trained specialist nurse should be involved from the outset to support the care of the patient and liaise between hospital services, primary care and specialist palliative care services.

- The diagnosis should be communicated skilfully and sympathetically with a clear picture of the disease and the management plan. This information should be communicated to the general practitioner immediately.

- Written information about the disease, its medicolegal aspects and relevant organisations should be available to the patient and family.

- Early pleurodesis is a key aim for symptom control and prevention of the development of a trapped lung.

- Palliative radiotherapy provides pain relief in about half of all patients.

- All patients with mesothelioma and performance status 0-2 should have the opportunity to discuss the merits of chemotherapy with a specialist experienced in the use of chemotherapy for malignant mesothelioma.

- Supportive and palliative care aims to provide relief from pain and other physical symptoms and to respond to emotional, psychological, social and spiritual needs.

- Dyspnoea, cough and other symptoms should be managed according to palliative care guidelines.

- Radical surgery should, for the foreseeable future, only be considered within randomised trials such as MARS and MesoVATS.

- Peritoneal mesothelioma is related to asbestos exposure but is less common than pleural mesothelioma.

Analyses of the British Mesothelioma Register by occupational group and geographical area support the conclusion that the continuing increase in deaths from mesothelioma in Great Britain is a consequence of past occupational asbestos exposure. ${ }^{3}$ These analyses show that occupations and geographical areas with the highest mesothelioma risks tend to be those clearly associated with heavy past asbestos exposuresfor example, within industries such as shipbuilding, railway engineering, asbestos product manufacture and construction. However, analyses of trends in risk over time are consistent with the notion that deaths due to specific high-risk industries of the past are levelling off or falling more recently as other sources of exposure have developed over a wider range of occupations and geographical areas. Workers with the highest risks today are likely to be those subject to incidental exposures during the course of their work such as building maintenance workers; nevertheless, the lifetime risk for most individuals is extremely small.

Measurements of airborne asbestos levels in buildings containing asbestos in good condition are typically several orders of magnitude below the lowest exposure levels seen in occupational cohorts of asbestos workers, and ambient asbestos levels in the general environment are likely to be even lower. ${ }^{6}$ Quantitative risk models derived from cohort studies may not be valid at these low levels, but they do indicate that substantial numbers of cases are unlikely to result from such exposures. ${ }^{13}{ }^{14}$

The risk of mesothelioma varies considerably in relation to the type of asbestos fibre, and there is evidence that the risks in relation to amphibole asbestos are considerably higher than chrysotile. ${ }^{15}$ Chrysotile was by far the most widely used type of asbestos in the UK. However, amosite was also used in substantial quantities and crocidolite to a lesser extent, as reflected in the figures on UK imports of the different asbestos types. ${ }^{16}$ Thus, many historical exposures are likely to have involved a mixture of fibre types, and the widespread use of chrysotile together with amphiboles in many asbestos products suggests that current exposures are likely to continue to do so.

Many thousands of workers have been exposed to asbestos fibres and have heard about the potential dangers, although only a small proportion will develop life-threatening disease as a result. These workers have justifiable anxiety about their future and may seek reassurance from the medical profession with routine chest radiographs. Although often requested by patients, annual radiographs of previously exposed individuals cannot be recommended. The current responsibilities of employers of workers who might be exposed to asbestos during the course of their work are laid out in the Control of Asbestos Regulations 2006 (Statutory Instrument 2006 No 2739). ${ }^{17}$ These Regulations describe the requirements for record keeping and medical surveillance, together with the actions to be taken if an employee is found to have a relevant disease.

The information now available about the risk of mesothelioma according to occupation, geographical area, birth cohorts and type of asbestos and age first exposed may allow advice about potential future risks in individual cases to be given in general and qualitative terms. Unfortunately, there is currently no basis for providing more specific advice to individuals.

\section{CLINICAL FEATURES}

Typically, presentation is either with chest pain, dyspnoea or both. ${ }^{18} 19$ The pain is usually dull, diffuse, occasionally pleuritic and characteristically worsens during the course of the illness. The pain may be described as heaviness or aching in the shoulder, arm, chest wall and upper abdomen. It sometimes has neuropathic components because of entrapment of intercostal thoracic, autonomic or brachial plexus nerves. Occasional patients are encountered who present with persistent chest wall pain with clear chest radiographs who develop either pleural masses or effusions during follow-up in the subsequent months. Cough may occur, particularly in patients presenting with a pleural effusion, but this is not usually a prominent symptom. 
In the early stages, dyspnoea is usually caused by a pleural effusion but later may be due to the restrictive effects of pleural thickening. A chest wall mass, weight loss, abdominal pain and ascites (due to peritoneal involvement) are less common presentations. Profuse sweating may occur.

Occasionally the diagnosis is suspected following a routine chest radiograph. Pleural thickening or a mass may be visible on the chest radiograph after drainage of a presenting effusion and may prompt consideration of the diagnosis, as may the finding of other manifestations of asbestos exposure such as pleural plaques. Bilateral disease occurs rarely at presentation but is not uncommon in the terminal phases. A further uncommon but well-recognised presentation is with a pneumothorax.

Unlike carcinoma of the bronchus, presentation with cervical adenopathy, haemoptysis, non-metastatic syndromes and symptoms due to distant metastases is unusual. The disease is more likely to progress by local extension than haematogenous spread. Direct involvement of mediastinal structures is common, but hoarseness and superior vena caval obstruction only rarely cause major symptoms. Dysphagia, if it occurs, tends to be a pre-terminal event.

Sometimes patients present with acute pleuritic chest pain and a small effusion but initial investigations may fail to give a diagnosis. The patient may then remain symptom-free for many months until recurrence of the fluid or the development of chest pain leads to further investigation and ultimate diagnosis of mesothelioma.

Physical signs depend on the type of disease involvement and include signs of pleural thickening and effusion together with restriction of expansion of the hemithorax. Finger clubbing occurs more commonly in mesothelioma than in other forms of asbestos-related pleural disease. ${ }^{20}$ Pericardial involvement may result in signs of tamponade. Weight loss may be prominent as the disease progresses.

Progression of the disease may be variable. Some patients have periods of apparent stability while others have relentless rapid deterioration.

\section{Key points}

- Malignant mesothelioma should be considered in any patient with either pleural fluid or pleural thickening, especially if chest pain is present.

- It may occasionally present with persistent unexplained chest pain and a normal chest radiograph.

- Symptomatic metastatic disease is unusual at presentation.

\section{PROGNOSIS}

Several studies have reported survival data, some measuring survival from date of onset of symptoms and others from date of definite diagnosis. A series reported from the UK showed an overall median survival from symptom onset of 14 months and confirmed a worse prognosis in those with sarcomatoid histology. ${ }^{5}$ A study of asbestos insulation workers in the USA showed that, among 141 cases of pleural mesothelioma, 36\% died within 6 months, 64\% within 12 months and 94\% within 24 months of the onset of symptoms. Of 244 cases of peritoneal mesothelioma, 55\% died within 6 months, 88\% within 12 months and $98 \%$ within 24 months of onset of symptoms. In this series the median survival for pleural mesothelioma from onset of symptoms was 10 months and from diagnosis 5 months. ${ }^{21}$ The high number of patients with peritoneal mesothelioma is thought to reflect very heavy asbestos exposure in this group of workers. Survival data are difficult to interpret and compare because they vary in starting point.
Future studies should be based on date of acceptance of diagnosis by a multidisciplinary team.

There are prognostic factors that allow some refinement of prediction of life expectancy. Apart from non-epithelioid histology, the most important poor prognostic factors are male gender, advanced stage disease, ${ }^{22} 23$ poor performance status, leucocytosis and thrombocytosis. Several scoring systems such as the European Organisation for Research and Treatment of Cancer (EORTC) and Cancer and Leukaemia Group B (CALGB) have been used extensively in chemotherapy trials and have been validated as useful in estimating survival.

The few patients who survive $>3$ years are almost exclusively from the epithelioid group. Distant metastases occur commonly, although they are usually late and seldom cause problems. Yates et $a l^{5}$ reported their presence in $>50 \%$ of cases at autopsy and with similar frequency in all histological types, although Law et $a^{23}$ found them more commonly in the sarcomatoid variety.

\section{Key points}

- Median survival varies from 8 to 14 months in different studies.

- Survival should be measured from the date of acceptance of the diagnosis by a multidisciplinary team.

- The disease is inexorably progressive with a very poor 5-year survival.

- Epithelioid tumours have a better prognosis than other cell types.

\section{DIAGNOSIS}

\section{Diagnostic strategy}

It is essential to use the combination of history, examination, radiology and pathology to reach a diagnosis of malignant mesothelioma. All the above elements are needed, and the overall strategy for diagnosis in a case of suspected mesothelioma is therefore to ensure that the patient has the relevant investigations rapidly and efficiently. In a clear-cut case it is possible to inform a patient of the diagnosis immediately a biopsy result is available, but in many cases it is usually wiser to defer this until the case has been discussed in detail at the local multidisciplinary team meeting and a diagnosis agreed. This also enables a preliminary view about management strategy to be given.

\section{History}

The history of asbestos exposure is very important but is often not recalled by the patient at presentation. An occupation may strongly suggest that exposure has occurred, although it is important to recognise less obvious occupations such as teacher, decorator and assembly worker. The possibility of neighbourhood or para-occupational exposure needs to be considered.

Further history at other stages of the patient's pathway is often much more informative after the patient has been able to think over his or her employment history. It has to be borne in mind that many patients will be attempting to recall working conditions up to 50 years earlier.

\section{Physical examination}

Physical examination does not usually aid the differential diagnosis. Occasionally tumour tissue may be felt between the ribs.

\section{Investigations}

Plain chest radiographic abnormalities may strongly suggest a malignant process. The key investigations subsequently are a pleural tap if an effusion is present and a contrast-enhanced CT 
scan, together with an appropriate biopsy procedure ${ }^{24}$ (see later sections).

A pleural tap can be performed in the outpatient clinic and the fluid should be sent for cytology and immunocytochemistry on a cell block. The risk of seeding from a pleural tap site is thought to be low, but the site of a puncture should be recorded.

If the clinical, radiological and cytological results subsequently support a diagnosis of mesothelioma, then this can be accepted. However, although immunocytochemistry can reliably show that cells are mesothelial in origin, it may be difficult to distinguish malignant from highly reactive cells. A biopsy is recommended if there is doubt about the diagnosis on radiological or clinical grounds as cytology may be unreliable.

In general medical practice it is not uncommon for a patient to have an undiagnosed pleural effusion despite a pleural tap and a CT scan. A potential diagnosis of mesothelioma may not have been considered by the managing team. For this reason, institutions are recommended to have a policy of prompt referral of such cases for a respiratory opinion.

A biopsy is required if the diagnosis is not clear after the pleural tap and a CT scan. The choices of technique are an ultrasound or CT-guided percutaneous pleural biopsy, or a thoracoscopic biopsy. Blind biopsy techniques are quick to perform and inexpensive, and are thus still used in some centres. However, a recent study has shown that a blind
Abrams' punch biopsy is less effective at reaching a diagnosis for pleural thickening than a CT-guided biopsy, and the latter is therefore preferable. ${ }^{25}$

Thoracoscopy is appropriate where there is pleural fluid and the technique facilitates not only complete drainage of the fluid and biopsy, but also immediate talc pleurodesis where appearances are clearly malignant. Where there is doubt about the macroscopic appearance, pleurodesis should be deferred. Biopsies are essential even if the appearances seem to be those of normal pleura.

The multidisciplinary team and the uncertain diagnosis Sometimes, even after cytology, biopsy and a detailed multidisciplinary team discussion, there is uncertainty about the diagnosis of malignant mesothelioma. This may be strongly suspected but not diagnosable with certainty, and this uncertainty should be communicated to the patient even if he or she has to be managed with mesothelioma in mind. Occasionally, as indicated above, a diagnosis of malignant mesothelioma only emerges after time and repeated CT scans and/or biopsies. This strategy needs to be carefully explained to patients and their families. Most equivocal cases eventually turn out to have mesothelioma when indolent disease is accompanied by negative biopsies. Persistent effusions are unusual in the presence of benign pleural thickening. Difficult cases should be reviewed by a regional specialist

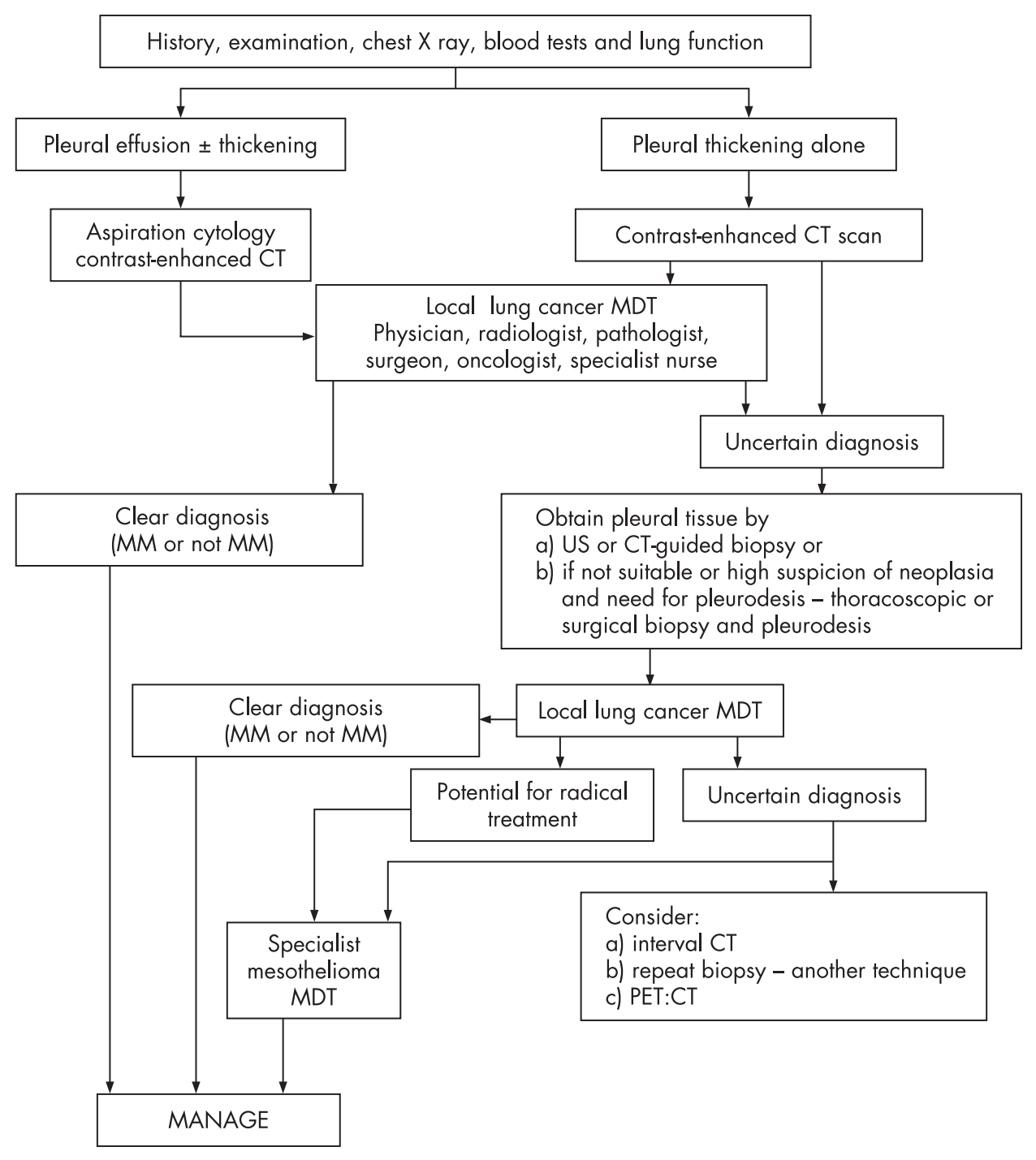

Figure 1 Suspected malignant mesothelioma: diagnostic algorithm. MM, malignant mesothelioma; CT, computed tomography of thorax; US, ultrasound; PET, positron emission tomography; MDT, multidisciplinary team meeting. 
multidisciplinary team as recommended in the Department of Health Framework document. ${ }^{2}$

The points made in this section are summarised in the diagnostic algorithm shown in fig 1 .

\section{Key points}

- A detailed occupational history is essential.

- Any patient in whom mesothelioma is suspected should be promptly referred to a respiratory physician for further assessment.

- Pathological confirmation of the diagnosis is recommended unless the patient is frail or has extremely advanced disease.

- Negative pleural biopsy and cytological results do not exclude mesothelioma and should lead to further investigation or follow-up.

- CT scanning plays a key role in the diagnosis of mesothelioma.

- CT scanning, ultrasound and thoracoscopic biopsy are the preferred techniques for obtaining tissue.

\section{DIAGNOSTIC IMAGING Imaging at presentation}

The initial chest radiographic appearances of malignant mesothelioma may range from normal in early disease to complete opacification of a hemithorax, depending on the amount of pleural thickening and fluid present. The pleural thickening may manifest itself as discrete pleural nodules or may progressively encase the lung. The mediastinum may be either central or displaced. There should be a clear rapid referral mechanism in place if either a chest radiograph or a CT scan suggests malignant pleural disease. ${ }^{2}$ A second copy of the radiologist's report should ideally be sent electronically or by facsimile to a designated member of the lung cancer multidisciplinary team, usually the chest physician.

Ultrasound can be very useful in identifying pleural abnormalities. The presence of a pleural effusion acts as an acoustic window, enabling the detection of intrapleural and intrapulmonary processes. Pleural effusions and thickening can be readily appreciated by ultrasound and discrete malignant nodules may be seen. ${ }^{26}$ Ultrasound-guided biopsy of pleural thickening and drainage of effusions are well-established safe techniques.

\section{Computed tomography (CT)}

Contrast-enhanced CT is the primary imaging modality used for the evaluation of suspected malignant pleural disease. Malignant or inflammatory pleural disease enhances strongly, and the contrast allows differentiation between thickened pleura, effusion and underlying aerated or collapsed lung. Multi-detector CT allows a scan of the entire chest to be performed in $<10 \mathrm{~s}$. A scan delay of $60 \mathrm{~s}$ allows optimal visualisation of pleural disease while still allowing assessment of the mediastinal nodes and liver in the portal venous phase of enhancement. A standard protocol includes the liver and adrenal glands but should also include the lower abdomen and pelvis if there is a past history of malignancy in the abdomen or pelvis or clinical evidence of pelvic disease.

Leung et al studied 74 consecutive patients with diffuse pleural disease. ${ }^{27} \mathrm{CT}$ features used to distinguish malignant from benign pleural disease were (1) circumferential pleural thickening, (2) nodular pleural thickening, (3) parietal pleural thickening $>1 \mathrm{~cm}$, and (4) mediastinal pleural involvement. The specificities of these findings were 100\%, 94\%, 94\% and $88 \%$, respectively. The sensitivities were $41 \%, 51 \%, 36 \%$ and $56 \%$, respectively. While the positive predictive value of these signs is high, their absence does not exclude a diagnosis of pleural malignancy and CT cannot reliably differentiate malignant mesothelioma from other malignancy. Others have confirmed that the commonest features of malignant mesothelioma are circumferential nodular lung encasement, pleural thickening with irregular pleuropulmonary margins and pleural thickening with superimposed nodules. ${ }^{28}$ These CT findings may be important for a working diagnosis in patients with poor performance status who do not want, or are unfit for, invasive biopsy procedures. Coincidental pleural plaques are found on the CT scan in approximately $20 \%$ of patients with malignant mesothelioma and there may be other features of asbestos exposure. Conversely, in many patients there may be no other radiological evidence of asbestos exposure. CT evidence of distant metastases is rare at presentation in malignant mesothelioma.

\section{Magnetic resonance imaging (MRI)}

MRI has a limited role in the evaluation of malignant mesothelioma. Pleural malignancy enhances avidly with use of gadolinium-based contrast material. Anatomical and morphological MRI features similar to those seen at CT are used to differentiate between benign and malignant disease and to establish local invasion. ${ }^{29}{ }^{30}$ MRI, with its ability to scan in any plane, has been used to accurately assess resectability prior to radical surgery. ${ }^{31}$ Multi-detector CT scanning is able to provide detailed reconstructions, thus giving MRI only a limited role in evaluating patients with questionable areas of local tumour extension at CT or in whom intravenous administration of iodinated contrast material is contraindicated.

\section{${ }^{18} \mathrm{~F}$-fluorodeoxyglucose positron emission tomography (FDG PET)}

In a limited number of patients where conventional imaging and biopsy have been either unhelpful or equivocal, FDG PET may be useful in differentiating benign from malignant pleural disease and might guide choice of biopsy site. Duysinx et al studied 63 patients with FDG PET and found this to have a sensitivity for detecting malignancy of $96.8 \%$ and a specificity of $88.5 \%{ }^{32}$ False positive results may be seen in cases of parapneumonic effusion and both tuberculous and uraemic pleural disease. ${ }^{33}$ Care should be taken with patients who have previously undergone talc pleurodesis, as the inflammatory process caused by this procedure can also cause a false positive result. ${ }^{34}$ It is not known how long the scan remains positive after pleurodesis.

The standardised uptake value (SUV) is used as a semiquantitative measure of the metabolic activity of a lesion. The SUV is significantly higher in malignant mesothelioma than in benign pleural diseases such as inflammatory pleuritis and asbestos-related pleural plaques. ${ }^{35}$ However, some cases of malignant mesothelioma are low-grade tumours and may not be avid on FDG PET. SUV can be taken at any time following injection of the tracer. There is neither an accepted time at which SUV should be measured in patients with malignant mesothelioma nor a particular threshold able to differentiate between benign and malignant disease. Volume measurements can be taken using SUV, and this offers the potential for assessing disease response following either chemotherapy or other novel treatment.

\section{Imaging and staging}

The TNM staging system proposed by the International Mesothelioma Interest Group (IMIG) is used for assessing patients with potentially resectable disease (see Appendix 2 available online at http://thorax.bmj.com/supplemental). ${ }^{36}$ This staging system was designed as a surgical tool and may not be completely applicable to imaging. CT and MRI overall have 
fairly similar accuracies for staging malignant mesothelioma, but both techniques may underestimate the stage of the disease. ${ }^{37}$ Although both techniques have been shown to be sensitive in predicting resectability, ${ }^{38} \mathrm{CT}$ is routinely used in view of its speed of examination and availability. Radiological staging may be required for entry into a clinical trial.

Mediastinal nodes are commonly involved by mesothelioma and, as with the staging of lung cancer, CT has limited accuracy for detecting mediastinal node involvement. FDG PET also appears to be relatively poor at distinguishing mediastinal nodal metastases from adjacent mediastinal pleural involvement, although a high SUV seems to correlate with the presence of N2 disease. ${ }^{39}$ Co-registration of CT with PET images, "CT-PET", may have a role in assessing these patients but studies are limited at present. ${ }^{40}$ Currently, mediastinoscopy is normally performed before radical surgery to exclude patients with N2 disease. CT-PET may have a complementary role aiming to detect occult metastatic or N3 disease.

\section{Imaging and assessment of disease response}

The assessment of disease response is important in evaluating treatment in both everyday clinical practice and clinical trials. Solid organ tumours are normally measured with either bidimensional $^{41}$ or unidimensional measurements. Response Evaluation Criteria in Solid Tumours (RECIST) ${ }^{42}$ is based on the assumption that tumours are generally spherical, and that a maximal unidimensional measurement correlates well with an overall reduction in tumour size. Malignant mesothelioma tends to grow as a rind around the chest wall, and changes in tumour bulk tend to manifest as changes in tumour thickness perpendicular to the chest wall rather than the maximal tumour dimension. Studies have shown discrepancies between tumour measurement in malignant mesothelioma using the World Health Organisation (WHO) and RECIST criteria. ${ }^{43}$ The RECIST criteria have now been modified and validated with particular reference to malignant mesothelioma. ${ }^{44}$ Semi-automated three-dimensional measurements have been described but are not routinely used. ${ }^{45}$ Difficulties arise in patients who have undergone pleurodesis as this causes an inflammatory response and subsequent pleural thickening. If the patient is to undergo chemotherapy following pleurodesis or surgical decortication, a baseline scan should be performed immediately before this.

\section{Key points}

- Where a chest radiograph is suggestive of malignant pleural disease, a copy report should ideally be sent to a designated member of the lung cancer multidisciplinary team, usually the chest physician, and preferably electronically or by fax.

- The multidisciplinary team should have a mechanism in place to follow up these reports.

- In patients with suspected malignant pleural disease, a chest CT scan should be performed before pleural biopsy or thoracoscopy.

- CT scanning cannot reliably differentiate malignant mesothelioma from other causes of malignant pleural disease.

- Ultrasound-guided pleural aspiration should be used as a safe and accurate method of obtaining fluid if the effusion is small or loculated.

- MRI has a limited role in patients with malignant mesothelioma (over and above multi-detector CT).

- PET scanning may be useful in differentiating benign from malignant disease but further studies are needed.
- Radiological staging of patients with malignant mesothelioma should occur before radical surgery and before clinical trial entry.

\section{PATHOLOGY}

Pathological diagnosis may be obtained from cytology or histology. Cytological diagnosis is based either on sampling of effusion fluid or by percutaneous fine needle aspiration cytology of a region of pleural thickening. In specialist centres the sensitivity of the former technique can be up to $76 \%$ and the latter $78 \%{ }^{46}$ Immunocytochemistry can be applied to the cytological material (including cell blocks), which can fairly reliably identify that the cellular content is mesothelial. However, where there is poor clinical and radiological correlation, the pathological diagnosis should be based on tissue biopsy due to difficulties in distinguishing malignant mesothelioma cells from reactive mesothelial cells and other pleural malignancies in fluid. ${ }^{47} 48$

Percutaneous core biopsy may provide sufficient material on which to confirm a diagnosis of malignant mesothelioma and to perform ancillary studies. This is reported to have a higher yield $(86 \%$ sensitivity and $100 \%$ specificity) than closed Abrams' or Cope needle biopsy which only offers a sensitivity of $21-43 \%{ }^{49}$ Others have shown a sensitivity for needle biopsy of $60 \%$ with a single attempt and $85 \%$ with repeat biopsies. ${ }^{50}$ Thoracoscopy has a sensitivity of over $90 \%$ with a low complication rate $(10 \%) .^{51}$

\section{Separation of benign from malignant mesothelial proliferations}

Establishing the nature of the mesothelial proliferation present in a sample is one of the most challenging aspects of diagnosis. The US-Canadian Mesothelioma Reference Panel have produced guidance in this area. ${ }^{52}$ It recommends a conservative approach, with equivocal cases being labelled "atypical mesothelial hyperplasia" or similar and, if appropriate, further tissue sampled.

Pathologists should be prepared to submit samples for expert review in cases of diagnostic difficulty.

\section{Histopathological classification}

The precise cell of origin of malignant mesothelioma is unclear, but it is now suggested that tumours arise from submesothelial cells that have the ability to differentiate along diverse lines. Numerous histopathological subtypes of diffuse malignant mesothelioma have been described (table 1). It is important for the pathologist to be aware of these alternative forms but the WHO classification advises that, as these various subtypes have no particular prognostic significance, tumours should be classified into one of three main types: epithelioid, sarcomatoid (with desmoplastic mesothelioma being a particularly

Table 1 Varieties of diffuse malignant mesothelioma (main types shown in bold type)

\begin{tabular}{ll}
\hline Epithelial & Sarcomatoid \\
Tubulopapillary & Fibrosarcomatoid \\
Solid variant & Chondrosarcomatoid \\
Adenomatoid & Osteosarcomatoid \\
Small cell & Leiomyosarcomatoid \\
Clear cell & Malignant fibrous histiocytoma-like \\
Deciduoid & Lymphohistiocytoid \\
Adenoidcystic & Desmoplastic \\
Pleomorphic & Biphasic (= mixed) \\
Mucin-positive & Any combination across the above \\
& groups \\
\hline
\end{tabular}


Table 2 Histochemical and immunohistochemical methods used to differentiate mesothelioma from adenocarcinoma

\begin{tabular}{|c|c|c|}
\hline & $\begin{array}{l}\text { Epithelioid } \\
\text { mesothelioma }\end{array}$ & Adenocarcinoma \\
\hline \multicolumn{3}{|l|}{ Histochemistry } \\
\hline PAS & + (glycogen) & $\begin{array}{l}+ \text { (small amount of } \\
\text { glycogen with mucin) }\end{array}$ \\
\hline plus diastase & - (almost always) & + \\
\hline $\begin{array}{l}\text { Alcian blue } \\
\text { plus hyaluronidase }\end{array}$ & + & $\begin{array}{l}\text { May be }+ \\
\text { Usually still + }\end{array}$ \\
\hline Immunohistochemistry & - & \\
\hline Calretinin & + & - \\
\hline CK5/6 & + & - \\
\hline WT-1 & + & - \\
\hline Thrombomodulin & + & - \\
\hline HBME-1 & + & - \\
\hline $\mathrm{N}$-cadherin & + & - \\
\hline CEA & - & + \\
\hline MOC-31 & - & + \\
\hline Ber EP4 & - & + \\
\hline B72.3 & - & + \\
\hline LeuM1 (CD15) & - & + \\
\hline E-cadherin & - & + \\
\hline Lewisy (BG8) & - & + \\
\hline TTF-1 & - & + (lung and thyroid) \\
\hline Others & Either & Or \\
\hline
\end{tabular}

Note that all may give aberrant or unexpected results occasionally and need to be assessed in combination, and also that adenocarcinomas from nonpulmonary sites may show different expression (for sensitivities and specificities see King et $a^{53}$ and Ordonez ${ }^{54}$ ).

aggressive form of the latter) and biphasic. Classification into these three main groups is important as it may alter management.

\section{Ancillary tests}

Despite the numerous publications describing the usual morphological features of mesothelioma, confirmation requires support from additional studies which may include histochemical, immunohistochemical and electron microscopic analysis. Unfortunately, no single stain or test can unequivocally confirm or exclude a diagnosis of mesothelioma and a panel of tests are performed, particularly when trying to differentiate mesothelioma from adenocarcinoma.

Epithelioid mesotheliomas can mimic (and be mimicked by) several other tumours, most frequently metastatic adenocarcinoma. The most useful differentiating histochemical stains are those for mucins (table 2). Two recent publications have reviewed the immunohistochemical profile of mesotheliomas compared with metastatic adenocarcinoma, which most commonly spreads from the lung. ${ }^{53}$ These confirm that a panel of antibodies is required and the most useful are listed in table 2. Most pathologists employ a limited combination of these markers with a mixture of positive and negative results indicating the diagnosis.

Immunohistochemistry is useful in differentiating between reactive and neoplastic mesothelial proliferations, particularly in cytological preparations or superficial biopsies. EMA is more likely to be positive in a neoplastic process, with more extensive p53 expression, while desmin decorates reactive mesothelial cells preferentially. ${ }^{55}$ The usual markers, however, are of much less value when trying to confirm the diagnosis of sarcomatoid malignant mesothelioma, where the sensitivity and specificity is much lower. ${ }^{56}$

Immunohistochemistry is useful in differentiating mesotheliomas from tumours other than adenocarcinoma (whether primary or metastasic). Table 3 lists most of the important differential diagnoses of diffuse malignant mesothelioma with antibodies that may aid diagnosis.
Electron microscopy can play a role in the diagnosis by demonstrating the long slender microvilli of mesotheliomas that contrast with the broader, blunt microvilli of adenocarcinomas.

\section{Specific types of mesothelial tumour}

Well-differentiated papillary mesothelioma

This is a rare tumour (fewer than 50 cases in the world literature) that deserves mention because of its confusing name and more indolent course and prolonged survival. Asbestos exposure has been reported in some cases of this tumour, but a genuine epidemiological association has not been established. It can be either localised or diffuse, and is more commonly found in the peritoneum of women. However, cases in the pleura are recognised (where the sex bias is less obvious). ${ }^{57}$

The typical microscopic appearance is of broad fibrovascular cores covered by a single layer of bland mesothelial cells. There are no mitoses and invasion of the underlying stroma is not seen. If this diagnosis is made pathologically but the disease proves to be rapidly progressive, then the correct diagnosis is probably a diffuse epithelioid malignant mesothelioma and further tissue sampling is indicated.

\section{Multicystic mesothelial proliferation}

This is a multicystic proliferation of mesothelial cells which has previously been considered by some to be a reactive process and by others a benign neoplasm. It is most frequently seen in the abdomen of premenopausal women and is sometimes associated with previous surgery or endometriosis. It is characterised by multiple fluid-filled cysts lined by flattened mesothelial cells. It is now clear that the condition can also be found both in the pleura and in men. It invariably has a benign clinical course.

\section{Solitary fibrous tumour (localised fibrous tumour/ mesothelioma)}

This is an uncommon spindle cell neoplasm that occurs most frequently in the chest but which can occur in virtually any site in the body; it should not be confused with localised malignant mesothelioma ${ }^{58}$ which is a localised form of the diffuse tumour described above. Solitary fibrous tumour characteristically arises from the visceral pleura, is well circumscribed and may be pedunculated. The microscopic hallmark is a bland spindle cell proliferation arranged in a "patternless pattern". The cellularity is variable with cellular areas interspersed with hypocellular collagenised regions. Vessels are usually prominent. Tumour can be infiltrative and cells are usually positive for CD34 and bcl-2 while cytokeratin antibodies are almost always negative. These tumours generally are benign, although occasionally malignant behaviour is recognised. The malignant varieties tend to cellularity, cellular atypia and high mitotic activity ( $>4$ per 10 high paver fields). Approximately 15\% of cases have hypertrophic pulmonary osteoarthropathy and 15\% have recurrent hypoglycaemia.

\section{Key points}

- The pathological diagnosis of a diffuse malignant mesothelioma is not always straightforward and interpretation should always be taken in context with full knowledge of the clinical history, examination findings and radiological appearance.

- Pleural fluid cytology and histology of blind biopsy specimens have a low diagnostic yield for mesothelioma but are important initial steps in differential diagnosis.

- Pathologists should attempt to specify the histological type of mesothelioma. 


\begin{tabular}{|c|c|}
\hline Differential diagnosis & Immunohistochemistry that may help \\
\hline \multicolumn{2}{|l|}{ Primary pleural tumours } \\
\hline Angiosarcoma & CD34, CD31, FVIIIRA \\
\hline Epithelioid haemangioendothelioma & CD34, CD31, FVIIIIRA \\
\hline Synovial sarcoma & $\begin{array}{l}\text { Cytokeratins, CD99, bcl-2, } \\
\text { cytogenetics }\end{array}$ \\
\hline Sarcomas (various) & Various depending on type \\
\hline Localised malignant mesothelioma & None \\
\hline Solitary fibrous tumour & $\mathrm{CD} 34, \mathrm{bcl}-2, \mathrm{CD} 99$ \\
\hline $\begin{array}{l}\text { Well-differentiated papillary } \\
\text { mesothelioma }\end{array}$ & $\begin{array}{l}\text { None (needs macroscopic } \\
\text { appearance and usually peritoneum) }\end{array}$ \\
\hline Adenomatoid tumour & $\begin{array}{l}\text { None (needs macroscopic } \\
\text { appearance) }\end{array}$ \\
\hline Calcifying tumour of the pleura & None (usually young patient) \\
\hline $\begin{array}{l}\text { Desmoplastic small round cell } \\
\text { fumour }\end{array}$ & $\begin{array}{l}\text { Cytokeratins, desmin, EMA, WT-1, } \\
\text { NSE }\end{array}$ \\
\hline $\begin{array}{l}\text { Thymic tumours } \\
\text { Lymphoma }\end{array}$ & $\begin{array}{l}\text { Cytokeratins, EMA, occasionally CD5 } \\
\text { Lymphoid markers }\end{array}$ \\
\hline \multicolumn{2}{|l|}{ Metastatic tumours } \\
\hline Carcinomas & Cytokeratins \\
\hline Sarcomas & Various depending on type \\
\hline $\begin{array}{l}\text { Lymphomas } \\
\text { Malignant melanoma }\end{array}$ & $\begin{array}{l}\text { Lymphoid markers } \\
\text { S-100, HMB45, melan-A }\end{array}$ \\
\hline Thymic tumours & Cytokeratins, EMA, occasionally CD5 \\
\hline \multicolumn{2}{|l|}{ Non-neoplastic mimics } \\
\hline Pleural fibrosis & Rarely cytokeratins \\
\hline Reactive mesothelial cells & Desmin, EMA, p53 \\
\hline
\end{tabular}

- A selection of special stains must be used to confirm mesothelial origin of a tumour and aid differentiation from other pleural neoplasia.

- Pathologists should be prepared to submit samples for expert opinion in cases of diagnostic difficulty.

\section{Role of serum markers in diagnosis}

Two recent studies have described the use of serum markers in the diagnosis of malignant mesothelioma. Osteopontin is a bone-derived glycoprotein that is overexpressed in a number of malignancies including lung, breast, gastrointestinal tract and ovarian tumours. In patients with malignant mesothelioma, serum levels were raised in comparison with both healthy subjects and asbestos-exposed controls. The levels in exposed individuals with pleural plaques with pulmonary fibrosis were raised, but not to the same extent as those measured in patients with malignant mesothelioma. Using a cut-off value of $48 \mathrm{ng} /$ $\mathrm{ml}$, the assay had a sensitivity of $78 \%$ and a specificity of $85 \% .{ }^{59}$ Soluble mesothelin-related proteins (SMRP) are thought to be involved in cell adhesion and its monoclonal antibody binds to normal mesothelial cells, mesotheliomas and some ovarian cancers. Raised SMRP levels were found in 37 of 44 individuals with malignant mesothelioma (sensitivity $84 \%$ ) and only 3 of 160 patients with fibrosis, benign pleural disease and nonmesothelioma cancers. Seven of 40 individuals with asbestos exposure had raised SMRP levels, and 3 of these apparently disease-free individuals subsequently developed malignant mesothelioma. ${ }^{60}$ Epithelioid tumours were more likely to be associated with raised SMRP levels, and the levels appeared to correlate with tumour size and fell following surgical debulking. A recent larger prospective multicentre study ${ }^{61}$ confirmed higher levels of SMRP in malignant mesothelioma in comparison with both other malignancies with pleural involvement and benign asbestos pleural disease; however, the test was less sensitive than initially reported when distinguishing pleural metastasis from malignant mesothelioma (58\%). There was a clearer distinction when SMRP was measured in pleural fluid and the levels tended to be considerably higher.

Diagnosis at an early stage of the disease should, in theory, improve prognosis and identify patients for whom radical treatment might be indicated. The rate of false positives in exposed healthy individuals must cause concern and would engender considerable anxiety in a cohort of exposed men who, in all likelihood, will never develop malignant mesothelioma. Before large-scale screening with tumour markers can be recommended, prospective studies will be required to confirm sensitivity and specificity of the test, the natural history of an individual with an increased level of the marker and, ideally, demonstrate an impact of the measurement on mortality. Meanwhile, data on SMRP might be studied prospectively as part of treatment trials. As yet, SMRP is not widely available commercially; however, a markedly increased level in an appropriate clinical context might increase diagnostic confidence in cases where tissue diagnosis is equivocal.

Cytogenetics may play a part in diagnosis in the future but at present is not routinely used as no single alteration or pattern of alterations is diagnostic.

\section{MANAGEMENT \\ General management}

Patients with mesothelioma should be discussed by a lung cancer and mesothelioma multidisciplinary team, be under the care of a specialist (usually a respiratory physician) and have a specialist nurse allocated to them. The multidisciplinary team should include core professionals as defined in the National Institute for Health and Clinical Excellence (NICE) guidelines and Department of Health Framework document. Where there is diagnostic difficulty or a possibility of radical treatment, the patient should be discussed at a specialist multidisciplinary team meeting.

The specialist nurse (usually a lung cancer or mesothelioma specialist nurse) should facilitate the pathway of care for the patient and the family throughout the illness, ensure good liaison between hospital services and primary care, and ensure access to specialist palliative care services as required. Patients should be advised who to contact in case of need. Further details are provided in a later section.

The diagnosis should be communicated skilfully and sympathetically. A clear picture of the disease and what to expect, including a realistic prognosis, should be given to the patient and, if appropriate, to families and carers. It is important to avoid a nihilistic approach. A copy record of the consultation could be offered to the patient. Immediate communication with the general practitioner should include the known extent of the disease, what was said to the patient and the management plan. ${ }^{62}$

Ongoing follow-up by a member of the multidisciplinary team (usually the respiratory physician) is recommended, even if there is no change in treatment, as it provides an opportunity for further discussion including issues of compensation and benefits, symptom control and provision of support. There should be continuing close liaison with the general practitioner and primary health care team. The patient should have access to a specialist nurse, usually the nominated key worker.

The relatives or carers and the general practitioner should be warned, at an appropriate stage, that a Coroner's post mortem examination will nearly always be required after the death of a patient with mesothelioma, and all deaths have to be reported to the Coroner (in Scotland the Procurator Fiscal).

\section{Key points}

- A patient with mesothelioma should be discussed at a multidisciplinary team meeting and be under the care of a specialist. 
- Where there is diagnostic uncertainty or where radical treatment is considered, cases should be referred to a specialist multidisciplinary team.

- An appropriately trained specialist nurse should be involved from the outset to support the care of the patient and liaise between hospital services, primary care and specialist palliative care services.

- The diagnosis should be communicated skilfully and sympathetically with a clear picture of the disease and the management plan. This information should be communicated immediately to the general practitioner.

- Written information about the disease, its medicolegal aspects and relevant organisations should be available to the patient and family.

- Assessment of psychological, social and spiritual needs of patient and family/carers should be undertaken at key points during the disease pathway. Information should be offered about appropriate support services.

- The general practitioner should be reminded that all deaths have to be reported to the Coroner (in Scotland the Procurator Fiscal); an inquest is usually required.

\section{Treatment strategy}

Essential management points to be considered on diagnosis are:

- Management of the pleural effusion.

- Indications for prophylactic radiotherapy to intervention sites.

- Indications for chemotherapy.

- Immediate supportive care requirements.

- Compensation issues.

- Suitability for radical surgery.

- Suitability for clinical trial entry.

- Referral to the specialist multidisciplinary team.

\section{Organisation of care}

This is discussed in detail in the Mesothelioma Framework document. ${ }^{2}$ The difficulties facing patients with malignant mesothelioma are diagnosis, palliation, allocation to a specialist treatment (eg, surgery), recruitment into randomised trials and obtaining advice about social, financial and legal issues. For these reasons, every patient has a right to have his or her disease considered by an experienced team with a declared interest in this cancer. The essential composition of such a team is a chest physician, a radiologist, a pathologist, a surgeon, an oncologist and a cancer nurse, all with expertise and an expressed interest in the disease. The team should have ready access to specialist palliative care services and opinions. If local services cannot meet these criteria, we consider it advisable that arrangements are made for the routine referral of patients with malignant mesothelioma to a team with the required attributes (the specialist multidisciplinary team). Such referrals could be managed by record review, teleconferencing or by attendance at a clinic, depending on individual circumstances. Ongoing care should continue to be with the local team if it is in the patient's best interest. We recommend that initially a network of identified cancer nurses with expertise in malignant mesothelioma is established to facilitate such referrals at a local level.

There is no evidence to support the contention that the management of a given number of cases of malignant mesothelioma per year provides evidence of expertise, either in individuals or a multidisciplinary team. An expressed and evident special interest may be more important, although we consider that teams diagnosing fewer than $10-15$ cases per year are unlikely to develop and retain the attributes required. A typical specialist multidisciplinary team would be expected to discuss a minimum of 25 cases annually. ${ }^{2}$

\section{Surgery}

The role of surgical resection in malignant mesothelioma is very uncertain. Two approaches can be taken. The more radical is extrapleural pneumonectomy (EPP) (sometimes referred to as pleuropneumonectomy). The less radical approach is a debulking operation (sometimes known as cytoreductive surgery), which is either performed at open thoracotomy or by videoassisted thoracic surgery (VATS). Both are being tested in randomised controlled trials (see below). Radical treatment should only be considered for patients with epithelioid tumours (although the Mesothelioma And Radical Surgery (MARS) trial has not made this distinction owing to unreliability of sampling techniques).

\section{Extrapleural pneumonectomy (EPP)}

This procedure was first described in the $1970 s^{63}$ and its aim is to eradicate all macroscopic disease, ideally with good clearance margins. The nature, extent, pattern of growth and proximity to major organs makes mesothelioma impossible to eradicate completely without resection of all the parietal and visceral pleura, the underlying lung, the diaphragm and the pericardium. Even then there are often doubts about resection margins. Operative mortality is $4-9 \%,{ }^{64}$ but significant complications from EPP occurs in over $60 \%$ of patients. ${ }^{63-67} \mathrm{~A}$ median survival of 19 months following this radical operation with adjuvant chemotherapy and radiotherapy has been reported in the largest series, but this is based on highly selected patients reported with no indication of the denominator from which they were drawn and no control or comparative group. ${ }^{68}$ There have been further series reporting "improved" outcomes following EPP with multi-modality therapy, but again with no control group. ${ }^{69-74}$

The absence of randomised controlled trials on the role of EPP for mesothelioma led a recent systematic review of surgical management to conclude that the role of EPP could not be defined. ${ }^{75}$ Currently, the MARS trial is recruiting in the British Isles in its pilot phase. This is a randomised study comparing EPP against no EPP surgery within the context of trimodality therapy (neoadjuvant chemotherapy and postoperative radical hemithoracic radiotherapy). The aim is to randomise 50 patients to determine the feasibility and acceptability of performing an adequately powered randomised trial. The primary outcomes of the main trial will be survival and quality of life. Patients being considered for EPP should be treated within the context of the MARS trial.

With potentially high mortality and morbidity, patients must undergo rigorous preoperative assessment before being considered for EPP. Fitness for surgery should be assessed according to standard BTS guidelines for pneumonectomy in lung cancer ${ }^{76}$ and should also include preoperative echocardiography to assess pulmonary artery systolic pressure.

Preoperative staging with a CT scan, PET scan and mediastinoscopy are important to assess resectability ( $\mathrm{Tl}-3$, N0-1, M0). Together with positive resection margins and nonepithelioid subtypes, involvement of mediastinal lymph nodes has been shown to be a negative predictor of survival following EPP. ${ }^{69} 77$ A PET scan, particularly integrated CT-PET imaging, identifies distant metastasis ${ }^{78}$ but is less good at identifying positive N2 lymph nodes owing to the proximity of the mediastinal pleura. Accurate staging of the mediastinum by mediastinoscopy is therefore required in the MARS trial in all 
patients for whom randomisation is being considered for possible EPP.

As most patients who present are usually already in advanced stages of the disease, only a minority may be eligible for EPP. Of these, it is likely that only a few will benefit from radical treatment with or without EPP. Until there is clear evidence for EPP, it cannot be recommended as the treatment of choice.

\section{Debulking/cytoreductive surgery}

This less radical approach, which can be performed by VATS or thoracotomy, involves removal of as much of the tumour burden as possible without removing the underlying lung, diaphragm or pericardium. Where the underlying lung is trapped by the diseased pleura, re-expansion of the lung may be possible following decortication, ${ }^{79}$ thereby offering symptom control with less morbidity.$^{80}$ VATS pleurectomy/cytoreductive surgery has been reported to be effective in preventing fluid recurrence $^{81}$ and may also be associated with increased survival $^{82}$ although, like EPP, it has not yet been tested in a randomised trial.

MesoVATS is an ongoing randomised study in the UK comparing VATS cytoreductive surgery against bedside talc pleurodesis in patients with a pleural effusion secondary to proven or suspected mesothelioma. Survival and quality of life are outcome measures, as well as clinical and cost effectiveness. Patients who present with a pleural effusion and have been deemed ineligible for the MARS trial should be considered for the MesoVATS trial.

Patients referred for radical surgery should be aware that it is likely to be either preceded or followed by chemotherapy and followed by hemithorax radiotherapy ("trimodality therapy"). Patients should be given realistic information about the perioperative risks and the chances of long-term survival.

\section{Key points}

- There are no randomised control trials to establish the role of radical surgery.

- Radical surgery should only be considered within a randomised trial.

- Surgery should be concentrated in centres where there is experience in performing extrapleural pneumonectomies.

- The present claims for benefit are for surgery within multimodality therapy.

- Patients should be aware of the potential for trimodality treatment and be given realistic information about outcomes.

\section{Management of pleural effusion}

One of the central aims in the management of patients with symptomatic pleural effusions caused by mesothelioma is to achieve an early and successful pleurodesis. This helps symptom control and a trapped lung is less likely to occur if the procedure is performed promptly. Given the low diagnostic yield of bedside procedures, early thoracoscopy also gives an opportunity to obtain a definitive histological diagnosis.

Thoracoscopy ${ }^{82-86}$ is an extremely useful technique in the evaluation and management of undiagnosed exudative pleural effusions. As well as providing a high diagnostic yield, it allows complete drainage of the pleural space followed by talc poudrage. Thoracoscopy can be performed under conscious sedation (usual for medical thoracoscopy) or under general anaesthesia (VATS). Complications are uncommon but include pleural space infection and surgical emphysema.

If the patient is either too frail to undergo thoracoscopy or a firm diagnosis has already been made, talc slurry pleurodesis may be performed via an intercostal drain..$^{87}$ Occasionally, simple repeated pleural aspirations without pleurodesis may be appropriate for very frail patients with advanced disease. Smallbore indwelling catheters and drainage systems are an alternative in these circumstances.

Chemical pleurodesis should be performed via a small bore (16-18F) that should be flushed regularly with normal saline to maintain its patency. ${ }^{89}$ Lignocaine $(3 \mathrm{mg} / \mathrm{kg}$; maximum $250 \mathrm{mg}$ ) should be administered intrapleurally just before sclerosant administration. In addition, premedication should be considered to alleviate anxiety and pain associated with pleurodesis. Satisfactory apposition of the parietal and visceral pleura should be confirmed radiographically. There are no data to suggest that suction improves the success rate, ${ }^{89}$ or that frequently changing the position of the patient improves either dispersion of the sclerosant or the success of pleurodesis. ${ }^{90} 91$

Currently the most effective freely available pleurodesis agent is sterile talc. ${ }^{88} 899293$ The dose of the talc should not exceed $4 \mathrm{~g}$, and it should be calibrated to avoid the rare risk of the development of adult respiratory distress syndrome. ${ }^{94}$ The intercostal tube should be clamped for $\mathrm{l} \mathrm{h}$ after sclerosant administration and, in the absence of excessive fluid drainage (>250 ml/day), removed 24-48 h later. Recent data showed no difference in success rates between talc poudrage and talc slurry. ${ }^{94}$

Pleuroperitoneal shunts have been used where pleurodesis has failed and for trapped lung. However, there is a high complication rate, including shunt occlusion and infection. Their use is therefore diminishing. ${ }^{95}$

Unfortunately, a minority of patients will have a trapped lung at presentation or develop the problem during the course of their disease. If asymptomatic, partial entrapment and little fluid production then no action is required. However, if there are symptoms due to rapid re-accumulation of pleural fluid, an indwelling pleural catheter may be inserted. Catheters may be inserted as day case procedures and, with nursing support, allow patients and their carers to drain their effusions at home. They have been shown to significantly improve the quality of life $^{96}$ and, with regular drainage, up to $45 \%$ of effusions undergo spontaneous pleurodesis. ${ }^{97}$ Complications are rare but include pleural infection. ${ }^{96}{ }^{97}$

None of the available techniques designed to control pleural effusion in malignant mesothelioma is universally successful. Patients and their carers should therefore be made aware of the risk of re-accumulation of pleural fluid and the methods of accessing the secondary care team-for example, via the cancer nurse specialist.

\section{Key points}

- Early pleurodesis is a key aim for symptom control and prevention of the development of a trapped lung.

- Thoracoscopy is an extremely useful diagnostic and therapeutic tool.

- Calibrated talc is the pleurodesis agent of choice.

- Indwelling pleural catheters are useful for symptom control in cases of trapped lung or where chemical pleurodesis has failed.

\section{Radiotherapy}

Radical radiotherapy as a single modality

Irradiation of the pleura is limited by toxicity to the lung and adjacent organs, particularly the bowel and stomach (for leftsided lesions). A retrospective review of 123 patients treated with hemithoracic radiation after surgical debulking of tumour (pleurectomy/decortication) showed actuarial local control at 1 year of $42 \%$ and median survival of 13.5 months. ${ }^{98}$ The lung is 
sensitive even to small (palliative) doses of radiation and, in the same study, severe pulmonary toxicity was found in $10 \%$ with $1.5 \%$ treatment-related mortality at 1 month. ${ }^{98}$ Hemithoracic irradiation with the lung in situ is therefore not indicated for mesothelioma.

\section{Palliative radiotherapy}

Retrospective and uncontrolled series suggest that radiotherapy can help relieve pain from mesothelioma in around half of patients treated. ${ }^{99} 100$ Although there are no controlled trials evaluating the effect of field size on pain relief, retrospective studies suggest that palliation of pain can be achieved by treating relatively small volumes of symptomatic disease and using short schedules ( $1-5$ fractions) of radiotherapy. ${ }^{100}$ Such schedules have been shown to be effective and well tolerated in palliating pain from both thoracic and non-thoracic malignancy. Large-volume radiotherapy has been used, but its effect is usually short-lived and the need to treat bulky disease (necessitating long treatment times) limits its usefulness. ${ }^{101}$ Patients with symptoms from mediastinal infiltration such as superior vena caval obstruction have a poor response to radiotherapy and generally have a short survival. Other means of palliation are more appropriate.

\section{Radiotherapy as an adjunct to surgery}

When extrapleural pneumonectomy is performed, radical radiotherapy is viewed as an integral part of management and can result in local control in $60-90 \%$ of patients, albeit with significant (though acceptable) morbidity. ${ }^{71}{ }^{102}$ Radiotherapy can be delivered with conventional techniques or with the aid of sophisticated planning and treatment hardware and software known as intensity modulated radiotherapy (IMRT). ${ }^{103}$ Preliminary evidence suggests that this technique does result in improved local control over more traditional ways of delivering radiotherapy. ${ }^{104}$ However, no improvement in overall survival has yet been observed as most patients develop progressive disease outside the hemithorax.

\section{Prophylactic radiotherapy}

There is a risk of seeding of malignant cells in the scar produced by biopsy and/or pleural drainage, resulting in an uncomfortable subcutaneous tumour (although ulceration is rarely a problem). A randomised trial has shown that the risk of this happening can be reduced from $40 \%$ to $0 \%$ by the administration of three fractions of radiotherapy to scars. ${ }^{81}$ Observational studies and first principles suggest that such treatment should be given promptly (ie, as soon as the wound has healed). However, a recent randomised trial showed that the use of a single dose of radiotherapy was ineffective for prophylaxis, with recurrences occurring in $10 \%$ of sites not given radiotherapy compared with $7 \%$ of sites irradiated. ${ }^{105}$ However, this study did show a trend for a lower prevalence of seeding with less invasive procedures. The overall rates of drain site disease were 22\% for Abrams' needles, 9\% for thoracic drains and 4\% for fine needle aspirates. Similarly, a randomised study of 61 patients given three fractions of radiotherapy showed no difference in the prevalence of wound seeding at 1 year with $23 \%$ of treated patients and $10 \%$ of controls developing scar-related nodules $(\mathrm{N}$ Rourke, personal communication).

The current recommendation is that patients of good performance status (and therefore longer survival) who have chest wall wounds should be referred for radiotherapy promptly and treated with a three-fraction schedule. If the patient is of poor performance status and/or has had a minimally invasive procedure, radiotherapy may be unnecessary. Tumour seeding can also occur in the abdominal wall after paracentesis for secondary thoracic malignant mesothelioma or primary peritoneal mesothelioma; however, the potential need for either repeated drainage of ascites or the use of an implantable device may limit the usefulness of prophylactic radiotherapy to this site.

\section{Key points}

- Palliative radiotherapy provides pain relief in about half of all patients.

- Palpable masses respond to radiotherapy in about half of all patients.

- Breathlessness and superior vena caval obstruction rarely respond to radiotherapy.

- Prophylactic radiotherapy may reduce chest wall implantation following invasive procedures, but may be most applicable for patients with a better prognosis and after more invasive procedures.

\section{Chemotherapy}

In general, palliative chemotherapy should be considered for all patients with performance status $0-2$. The objective response rate that should be expected is of the order of $20-40 \%$, and two randomised controlled trials have shown significant differences in survival between regimens, implying that chemotherapy may extend the life expectancy of some patients with mesothelioma. This benefit is not dependent on age, stage or histology. ${ }^{106-108}$ However, there is no randomised trial evidence showing that chemotherapy confers better quality of life and survival than supportive care without chemotherapy. These questions continue to be addressed by the BTS study MSO-1 which compares two alternative chemotherapy regimens (single agent vinorelbine and the combination of mitomycin, vinblastine and cisplatin) with active symptom control alone. ${ }^{109}$ This trial closed to recruitment with 409 patients randomised and the results are expected by late 2007 .

A number of phase II studies of various chemotherapy regimens have demonstrated both objective response rates comparable to those seen in advanced non-small cell lung cancer and worthwhile palliation of symptoms in half or more of the patients treated (table 4). Symptom relief may occur in patients whose tumours have not shown radiological response as defined by conventional criteria.

There has been considerable interest in a new chemotherapeutic agent for malignant mesothelioma, pemetrexed (Alimta; Eli Lilly). The main evidence supporting its use consists of a randomised study which compared a combination of pemetrexed and cisplatin (PC) with cisplatin (C) alone in patients with mesothelioma. The trial showed that the combination regimen extended median survival by nearly 3 months. ${ }^{106}$ On the basis of this study, the US Food and Drug Administration (FDA) approved pemetrexed for the treatment of mesothelioma and it has also been licensed for this indication in Europe, including the UK. Inclusion criteria included Karnofsky performance status (PS) $\geqslant 70$ corresponding to WHO or ECOG PS 0-1. Part way through the trial folic acid and vitamin B12 supplementation was introduced to reduce toxicity resulting in three patient subgroups: never supplemented (NS), partially supplemented (PS) and fully supplemented (FS). The sample size was substantially increased to ensure adequate statistical power of the FS subgroup; 456 patients were randomised but eight who did not receive chemotherapy were excluded from analysis. Patients in the PC arm received a median of six cycles while those in the $\mathrm{C}$ arm received a median of four cycles. NS patients received a median of two cycles on each arm. Median survival in the whole group was 12.1 months with PC and 9.3 months with $C(p=0.02)$. Among 331 FS patients, median survival was 13.3 months with PC compared with 10.0 months with C 
Table 4 Summary of phase II trials of chemotherapy for mesothelioma

\begin{tabular}{|c|c|c|c|c|c|c|}
\hline Chemotherapy regimen(s) & Number in study & $\begin{array}{l}\text { Tumour response } \\
\text { (partial) }\end{array}$ & $\begin{array}{l}\text { Medial survival } \\
\text { (months) }\end{array}$ & $\begin{array}{l}\text { Symptom relief } \\
(\%)\end{array}$ & Comments & Reference \\
\hline $\begin{array}{l}\text { Mitomycin, vinblastine, } \\
\text { cisplatin (MVP) }\end{array}$ & $\begin{array}{l}39 \text { (extended } \\
\text { study 150) }\end{array}$ & $\begin{array}{l}20 \% \text { (extended } \\
\text { study } 15 \% \text { ) }\end{array}$ & $\begin{array}{l}6 \text { (extended } \\
\text { study } 7 \text { ) }\end{array}$ & 62 & & 110,111 \\
\hline Vinorelbine & $\begin{array}{l}29 \text { (extended } \\
\text { study 65) }\end{array}$ & $\begin{array}{l}24 \% \text { (extended } \\
\text { study } 21 \% \text { ) }\end{array}$ & $\begin{array}{l}10.6 \text { (extended } \\
\text { study } 13 \text { ) }\end{array}$ & 50 & & 112,113 \\
\hline Gemcitabine and cisplatin & 21 & $47.6 \%$ & & & Benefit reported in symptoms & \\
\hline $\begin{array}{l}\text { Other gemcitabine and } \\
\text { cisplatin studies }\end{array}$ & & $16-33 \%$ & $9.6-13$ & & & $115-117$ \\
\hline Carboplatin & & $26 \%$ & 15 & & & 118 \\
\hline $\begin{array}{l}\text { Irinotecan, cisplatin, } \\
\text { mitomycin }\end{array}$ & & $35 \%$ & & & $\begin{array}{l}\text { Response in } 30 \% \text { of patients } \\
\text { previously receiving } \\
\text { chemotherapy }\end{array}$ & 119 \\
\hline
\end{tabular}

$(p=0.05)$. The investigators reported a tumour partial response rate of $41.3 \%$ in the PC arm, but a review by the FDA confirmed only half of these. ${ }^{120}$ Quality of life data, published in abstract form in 2003, reported a significant improvement in quality of life and symptom relief when compared with cisplatin alone. ${ }^{121}$ However, full quality of life data have not been published. The subsequent paper reported that 84 patients from the PC arm and 105 from the $\mathrm{C}$ arm received second-line chemotherapy which was associated with significant prolongation of survival after adjustment for baseline prognostic factors and treatment received. ${ }^{122}$ This strengthened the conclusion that first-line pemetrexed prolonged survival since the survival advantage was seen despite the fact that more patients in the $\mathrm{C}$ arm had received second-line chemotherapy. The subset analyses performed in this study mean that the results should be interpreted with caution. It is important to note borderline significance in survival advantage in the FS group, as well as the fact that the patients were younger and fitter than most with mesothelioma.

Two phase II studies have suggested that efficacy may be approximately similar when carboplatin (in a dose of area under the curve 5 ) is used instead of cisplatin in combination with pemetrexed. ${ }^{123} 124$ The substitution of carboplatin for cisplatin is associated with reduced symptomatic toxicity (particularly nausea and vomiting) and increased ease of administration with less need for prolonged hydration with intravenous fluids. This has the potential to improve quality of life.

Support for the efficacy of antifolates is provided by similar results from a smaller study of cisplatin with or without raltitrexed (another antifolate) in 250 patients with mesothelioma. ${ }^{125}$ Median overall and 1 year survival with cisplatin vs raltitrexed was 8.8 (CI 7.8 to 10.8 ) months vs 11.4 (CI 10.1 to 15) months and $40 \%$ vs $46 \%$, respectively $(p=0.05)$. There was no detriment to quality of life from raltitrexed. Unfortunately, the manufacturers do not intend to continue development of raltitrexed for treatment of mesothelioma and may stop production for economic reasons, leaving only pemetrexed in this class in the short to medium term.

The message from the randomised studies of pemetrexed and raltitrexed is that, unless cisplatin alone actually shortens survival-which seems unlikely-these drugs probably do confer a small median survival advantage and, as with any chemotherapy, patients whose tumours respond well to therapy are likely to gain more than average in terms of survival. The effects on quality of life are not yet fully evaluated but appear to be beneficial. Despite the need for caution in interpretation of the data, pemetrexed is an agent with demonstrable clinical efficacy in the treatment of mesothelioma and, as such, it is to be welcomed. It is less toxic than alternatives, particularly when used with carboplatin rather than cisplatin, and easily administered with a 3-weekly outpatient treatment schedule. Pemetrexed is the only drug licensed for the treatment of mesothelioma on the basis of randomised trial evidence and therefore may be considered the drug of first choice, used in combination with cisplatin or carboplatin. Other cheaper agents with useful activity include vinorelbine, gemcitabine, irinotecan and mitomycin, but none has yet been shown to confer a survival advantage in a randomised trial.

All patients who are fit enough to receive chemotherapy (all PS $0-1$ and some PS 2 patients) should therefore be given accurate information and should have the opportunity to discuss chemotherapy with a specialist experienced in its use for mesothelioma. Patients who prefer to receive chemotherapy after a discussion of the merits of this form of treatment should be offered it.

\section{Key points}

- Several chemotherapeutic agents can reduce tumour bulk and help symptoms. The combination of pemetrexed and cisplatin significantly prolongs survival compared with cisplatin alone.

- All patients with mesothelioma and performance status 0-2 should have the opportunity to discuss the merits of chemotherapy with either an oncologist or a respiratory specialist experienced in the use of chemotherapy for malignant mesothelioma.

- There are no published trials comparing either survival or symptom control in patients treated with chemotherapy or best supportive care. The results of the first such trial (BTS MSO-1) are expected by mid 2007.

- Further clinical trials of chemotherapy should be encouraged.

\section{New approaches to treatment}

Some new approaches to drug treatment of mesothelioma that may be important in the future are summarised in table 5 .

Attempts have been made to improve the outcome after surgery by use of additional treatment modalities. Cytoreductive surgery with intraoperative photodynamic therapy has been studied by several groups with disappointing results. ${ }^{132}$

\section{Supportive and palliative care}

Supportive and palliative care of patients with mesothelioma and their families is very important, given that the disease has a poor and relatively well-defined prognosis and that most patients need symptom palliation from the time of diagnosis onwards. The patient, family and general practitioner may often have difficulty in accepting that palliative care is the only 
Table 5 New approaches to treatment for mesothelioma

\begin{tabular}{|c|c|c|c|}
\hline Agent/approach & Mechanism of action & Trial evidence & Reference \\
\hline Bevacizumab (Avastin) & $\begin{array}{l}\text { Monoclonal antibody vascular endothelial growth } \\
\text { factor receptor agonist; angiogenesis inhibitor }\end{array}$ & $\begin{array}{l}\text { Proven efficacy in lung, colon, breast cancer. Multicentre trial } \\
\text { underway adding bevacizumab to gemcitabine and cisplastin }\end{array}$ & 126 \\
\hline Ranpirnase (Onconase) & Anti-tumour ribonuclease & $\begin{array}{l}\text { Phase III trial of doxorubicin with or without ranpirnase nearly } \\
\text { complete. Statins may reverse doxorubicin resistance }\end{array}$ & 127 \\
\hline Bortezomib (Velcade) & Proteosome inhibitor & $\begin{array}{l}\text { Proven efficacy in myeloma. Phase II (randomised) trial } \\
\text { underway in mesothelioma }\end{array}$ & 128 \\
\hline Arginine depletion & $\begin{array}{l}\text { Argininosuccinate synthetase, a rate-limiting } \\
\text { enzyme in arginine production is deficient in } \\
>50 \% \text { of mesotheliomas }\end{array}$ & Phase II clinical trial planned & 129 \\
\hline Immunotherapy & $\begin{array}{l}\text { Newer targeted biological agents are under } \\
\text { development }\end{array}$ & Interleukin-2 and interferon disappointing & 130 \\
\hline Gene therapy & $\begin{array}{l}\text { Attractive concept but unlikely to be able to } \\
\text { eradicate a solid tumour diagnosed late in } \\
\text { natural history }\end{array}$ & $\begin{array}{l}\text { Gene therapy no practical use outside small trials. Role may } \\
\text { be as part of multi-modality treatment }\end{array}$ & 131 \\
\hline
\end{tabular}

available treatment for the majority of cases. Anger and frustration are common, and there are particular issues in malignant mesothelioma concerning blame for the disease, obtaining benefits and litigation.

The National Institute for Clinical Health and Excellence ${ }^{62}$ describes supportive care as an umbrella term for services encompassing information giving, self-help and support, user involvement, symptom control, psychological support, social support, spiritual support, rehabilitation, complementary therapies, palliative care, end-of-life and bereavement care. Palliative care is described as the active holistic care of patients with advanced progressive illness. Management of pain and other symptoms and provision of psychological, social and spiritual support is paramount. The goal is achievement of the best quality of life for patients and their families. This document does not present a comprehensive account of supportive and palliative care and symptom relief, and more details can be found in standard references. ${ }^{133} 134$

Referral of the patient and/or their carers to specialist palliative care services is appropriate for a range of issues. These include unresolved symptoms and complex physical, psychosocial or spiritual needs, and end-of-life and bereavement issues.

\section{Key points}

- Most patients need symptom palliation from the time of diagnosis onwards.

- Supportive and palliative care aims to provide relief from pain and other physical symptoms and to respond to emotional, psychological, social and spiritual needs.

\section{Supportive care and the clinical nurse specialist}

Clinical nurse specialists have a central role in providing and coordinating the specialist supportive care needs of patients and carers. This includes liaising with services such as specialist palliative care, dietetics, physiotherapy and the spiritual team where advanced specialist supportive care is needed.

\section{Role of the lung cancer clinical nurse specialist}

Patients with malignant mesothelioma and their carers should have access to a lung cancer clinical nurse specialist or, where the local incidence of the disease is high, a mesothelioma clinical nurse specialist. Given the rarity of the disease, the complex support and information needs, it is appropriate for those diagnosed with peritoneal mesothelioma also to have access to the lung cancer clinical nurse specialist.
The role of the clinical nurse specialist includes the following core elements: $:^{135}$

- Communication

- Information

- Coordinated care

- Nursing assessment

- Patient advocacy

- Accessibility

- Support

\section{Communication}

It is usually the consultant that provides the patient with the diagnosis and an initial outline of management and prognosis, and support from a clinical nurse specialist is crucial at this stage. The clinical nurse specialist should be promptly available for further discussion of these issues with patients and their families and carers, and offer supportive information. Rapid communication with the general practitioner should be ensured and should include details of the known extent of the disease, what was said to the patient and the management plan.

It is not unusual for several members of the lung multidisciplinary team and the general practitioner to be involved in providing medical care, resulting in complex communication pathways that need to be maintained. The clinical nurse specialist should ensure that the patient and/or carer are aware of the need for a Coroner's post mortem examination and report to the Coroner or Procurator Fiscal and that this is confirmed in writing to the general practitioner.

\section{Information}

Patients with malignant mesothelioma and their families should have access to verbal and written information about the disease and its symptoms, end-of-life issues, treatments and the medicolegal implications. Regular contact with the clinical nurse specialist allows a steady flow of information according to the patient's needs.

Lung cancer clinical nurse specialists have expressed concerns about obtaining up to date information and maintaining knowledge and expertise in the field of mesothelioma. Information and support for nurses to allow them to meet the needs of their patients with malignant mesothelioma is available from the organisations listed in Appendix 3 (available online at http://thorax.bmj.com/supplemental). The clinical nurse specialist should advise (or clarify) patients and their carers that, following a diagnosis of malignant mesothelioma, entitlement to some benefits and allowances is automatic. Applying for benefits requires attention to detail and can be 
time-consuming. Patients and carers should be advised to make photocopies of everything they send to benefits centres for their own reference. The clinical nurse specialist should assist in directing or referring the patient and carer to an organisation that can help with the completion of benefit applications. The lung cancer clinical nurse specialist will advise patients about what help is available locally and Macmillan Cancer Support (on freephone 0800500800 ) can also direct people to local benefits advisory organisations. National organisations offering a telephone benefits advice service, including help with completion of claim forms, are listed in Appendix 3 (available online at http://thorax.bmj.com/supplemental).

\section{Coordinated care}

The clinical nurse specialist facilitates the pathway of care for the patient and the family throughout the illness, ensuring good liaison between hospital services and primary care and access to specialist palliative care services as required. Patients should be made aware of whom to contact in case of need. The community nursing team (palliative care or district nurse) should be made aware of patients diagnosed with malignant mesothelioma within their area. A team approach should then be adopted to meet the nursing needs of the patient.

\section{Nursing assessment}

It is good practice to ensure that there is assessment of the needs of both the patient and the family or carers. ${ }^{136}$ Assessment of patients should include physical symptoms and physical functioning, psychological problems, social care needs and need for spiritual support. Assessment of family members and carers includes their concerns and need for support, including eventually bereavement support. Such assessment may need to be repeated at key times during the illness.

\section{Patient advocacy}

The limited treatment options, variation in expert opinion and universally poor outcome means that patient preference is particularly relevant when making treatment decisions about malignant mesothelioma. The relationship between the clinical nurse specialist and patient should help elicit patient and carer hopes and expectations and ensure that treatment plans are mutually agreed upon.

\section{Accessibility}

Timely access to the health care team is vital to ensure rapid attention to symptoms. The clinical nurse specialist is often best placed to provide a contact point and should be aware of any other points at which the patient may contact the service.

\section{Support}

Patients should be directed to an appropriate cancer support group such as the Lung Cancer Support Group. Where there is a sufficient number of patients with malignant mesothelioma, the development of a local Mesothelioma Support Group is recommended. Patients' carers should be offered information about carer support when required.

\section{Key points}

- The lung cancer clinical nurse specialist acts as the key worker facilitating the pathway of care for the patient and the family throughout the illness.

- Clinical nurse specialists are pivotal to meeting patients' specific supportive care needs.

- Patients with malignant mesothelioma and their carers should have access to a lung cancer clinical nurse specialist.
- The clinical nurse specialist should maintain complex communication pathways.

- Providing information to people with cancer and carers should be an ongoing process.

- The clinical nurse specialist should provide help and guidance to patients and their carers concerning entitlement to benefits and allowances.

- Physical, psychological, social and spiritual assessment may need to be repeated at several key times during the illness.

- Patient preference is particularly relevant when making treatment decisions about malignant mesothelioma.

- Timely access to the health care team is vital.

\section{Symptom control}

All symptoms need a working diagnosis, as some may be caused by concurrent non-cancer related problems. It is often helpful to record symptom severity on a simple scale to assess progress and response to treatment. Relief of pain, breathlessness and other symptoms can occur with response to chemotherapy.

\section{Pain}

The treatment of pain in malignant mesothelioma follows the same principles as for any other cancer but can include more specific techniques where initial methods are inadequate. These may necessitate early referral to a specialist pain service. Specific techniques include:

- Transcutaneous electrical nerve stimulation machines and acupuncture.

- Intercostal, paravertebral or brachial plexus nerve blocks.

- Interpleural, ${ }^{136}$ epidural or intrathecal analgesic infusions.

- Local thoracic spine neurolytic blocks.

- Percutaneous cervical cordotomy ${ }^{137}$ (particularly when the patient is still ambulant).

In pain from chest wall involvement the response to opioids is variable because of added inflammatory and neuropathic components. In this situation, the following adjuvant analgesics should be considered early: non-steroidal anti-inflammatory drugs (with gastric cover); steroids (with gastric cover); noradrenergic antidepressants such as amitriptyline; or anticonvulsants such as gabapentin or carbamazepine.

Pain control will be improved by attention to emotional, psychological, social and spiritual problems. Distraction and relaxation techniques and complementary therapies may also be helpful.

Pain associated with localised tumour invasion of the chest wall may respond to radiotherapy. ${ }^{99}$

\section{Dyspnoea}

The common causes of breathlessness in mesothelioma are pleural effusion, lung compression and chest wall stiffness. Weakness and malaise, and anxiety or panic will also contribute. Progressive breathlessness should be treated according to general palliative care guidelines ${ }^{62}$ that include pharmacological approaches such as opioids, benzodiazepines and oxygen, and non-pharmacological methods such as breathing exercises and relaxation combined with re-adaptation. $^{138}$

Cough, anorexia, weight loss, fatigue, excessive sweating and depression all occur in malignant mesothelioma and should be managed according to palliative care guidelines. ${ }^{62}$ 


\section{Key points}

- Early involvement of a pain relief specialist is indicated if pain is not controlled after initial measures.

- Dyspnoea, cough and other symptoms should be managed according to palliative care guidelines.

\section{PERITONEAL MESOTHELIOMA}

The incidence of peritoneal disease, like pleural mesothelioma, has been steadily increasing over the last 30 years, but the ratio of pleural to peritoneal disease in an asbestos-exposed population remains high (in the order of 12:1) and is slowly increasing. Factors favouring the development of peritoneal disease appear to be longer, heavier exposure to asbestos and, perhaps, to mixed dust. Although the age distribution is similar to pleural disease, there is less male preponderance.

\section{Pathology}

The disease may be localised, multinodular or diffuse. Epithelioid subtypes are much more common with only about $15 \%$ of tumours being either mixed or sarcomatoid. In twothirds of patients the disease remains confined to the abdomen. The undersurface of the diaphragm is almost always involved, but tumour rarely penetrates through into the thorax. Spread to the omentum, pelvis and right subhepatic space is common.

Well-differentiated papillary and cystic mesotheliomas seem to be a separate disease, distinct from malignant peritoneal tumours. These conditions are unrelated to asbestos exposure, usually occur in women and have a good prognosis.

\section{Symptoms}

These are non-specific and include abdominal pains, constipation, weight loss, abdominal distension, palpable masses and ascites. Small bowel obstruction is usually a feature of the terminal stages.

\section{Imaging}

The optimal imaging modality is probably CT scanning. This may show omental and mesenteric thickening (the commonest findings), sheet-like masses, tumour nodules and usually only minimal ascites which may be loculated. The differential diagnosis includes peritoneal secondaries from adenocarcinoma, peritoneal endometriosis and pseudomyxoma peritonei. Retroperitoneal nodal enlargement is more in favour of an adenocarcinoma.

\section{Diagnosis}

Cytological examination of the ascitic fluid rarely gives an answer but fine needle aspiration of omental masses has been advocated. If the diagnosis is suspected, this can be confirmed by laparoscopy.

\section{Prognosis and treatment}

The prognosis is worse than for pleural mesothelioma. In one study the mean survival time was 7.4 months compared with 11.4 months in a group with pleural mesothelioma. ${ }^{21}$ Like pleural mesotheliomas, the epithelioid subtype seems to be associated with a better prognosis, as is youth and a good performance status. There is limited evidence to support the benefit of chemotherapy, although responses are reported and small case series suggest prolonged survival with regimes based on cisplatin and including mitomycin C, doxorubicin and pemetrexed. The role of radiotherapy is unclear and is associated with considerable morbidity but might be considered prophylactically to laparoscopy port sites. It has been suggested that debulking procedures may improve the response to chemotherapy but there are no controlled trials.
It is important to remember that the management of peritoneal mesothelioma should also include multidisciplinary patient care and consideration of medicolegal aspects.

\section{Key points}

- Peritoneal mesothelioma is related to asbestos exposure but is less common than pleural mesothelioma.

- The outlook is poor and no treatment has been shown to alter prognosis.

\section{BENEFITS AND COMPENSATION FOR MESOTHELIOMA}

The respiratory specialist and clinical nurse specialist are often best placed to advise patients and families about opportunities for compensation. The legal test is that the diagnosis and causation should be established on the balance of probability. Hence, pathological diagnosis is not mandatory for compensation issues, although an unequivocal diagnosis will remove subsequent room for debate. Patients who cannot identify occupational exposure to asbestos are not eligible for compensation.

Patients may be entitled to claim compensation in two ways:

(1) A claim for Industrial Injuries Disablement Benefit from the Department of Social Security (via the Benefits Agency) or through the War Pensions Scheme. Other benefits for incapacity and disability may also be payable.

(2) A Common Law claim for damages from the firm/firms where exposure to asbestos occurred.

\section{Industrial injuries disablement benefit (IIDB)}

Industrial injuries benefit is awarded under the terms of the Social Security Contributions and Benefits Act 1992. This Act specifies that the following criteria must be met to qualify for industrial injuries benefit:

(1) The person must be suffering from a prescribed disease or personal injury which developed after 4 July 1948.

(2) (a) The claimant must have been an employee, ie, not selfemployed and (b) they should have worked in a scheduled occupation, ie, one where there had been exposure to asbestos.

Mesothelioma is designated a Prescribed Disease (D3) under Schedule 1 of the Social Security (Industrial Injuries) (Prescribed Diseases) Regulations 1985. Under new regulations (The Social Security (Industrial Injuries) (Miscellaneous Amendment) Regulations 1997), the schedule of prescribed occupations was broadened to include any occupation in which there has been "exposure to asbestos, asbestos dust or any admixture of asbestos at a level above that commonly found in the environment at large". Thus, work may not have involved the actual handling of asbestos but may have been carried out in its presence, sometimes known as para-occupational exposure.

\section{Procedure for claiming benefit}

A claim for IIDB is made by contacting the local Jobcentre Plus or by ringing the Department of Works and Pensions (DWP) enquiry line (0800 882200 ) and asking to be sent form Bl 100 $\mathrm{PN}(\mathrm{A})$. A supply of these forms should be available in chest clinics and the doctor or clinical nurse specialist should provide confirmation of the patient's diagnosis in writing. Occasionally the claimant may need help with completion of the form. Leaflets SD5 ("Ill or Disabled because of Work") and NII2 ("If you have an Industrial Disease") may also be helpful.

In 2005 the Industrial Injuries Advisory Council reviewed the term of prescription for all asbestos-related diseases. They 
concluded that those for mesothelioma did not require any modification. However, they noted that the uptake of IIDB was less than the Council would have expected and therefore recommended various measures to raise awareness of the provisions of the scheme, one of which has been liaising with the British Lung Foundation to ensure that clinical nurse specialists are fully aware.

Another concern of the Council was the issue of prompt payments for terminally ill claimants, including all cases of malignant mesothelioma. The "90 day" rule for most benefits has already been waived, and measures have been put in place to reduce any administrative delays to a minimum. Providing the claimant qualifies, he or she should get 100\% disability benefit backdated to the date of diagnosis/application. Currently, this is approximately $£ 120$ per week.

The Council also recognised that, although such claimants are assessed at $100 \%$ disablement, because of their poor life expectancy they receive only a fraction of the total amount payable compared with those suffering from less severe prescribed diseases. The Government has indicated that it intends to put in place a long-term solution to ensure that sufferers of malignant mesothelioma can receive compensation so that they themselves can benefit from it while knowing that their families are secure in the future. The Government is presently going out to consultation, and it is anticipated that they will be making some changes to the way in which mesothelioma sufferers are compensated during 2007.

\section{War pensions scheme}

Mesothelioma caused by asbestos exposure during service in the defence forces is compensated under the War Pensions Scheme. A claim should be registered with the War Pensions Agency; details of the local office should be in the telephone book or enquires can be made from the Veterans Agency help line (0800 1692277 ). Those in receipt of IIDB cannot also receive a War Pension, and vice versa.

\section{Additional benefits payable for incapacity and disability}

Patients should obtain Benefits Agency leaflet SDl "Sick or Disabled" (available in tape, Braille and a number of languages). This gives full details of the various additional benefits for which they may be eligible:

(1) Income replacement:

(a) For those with adequate National Insurance contributions: Statutory Sick Pay (SSP) or Occupational Sick Pay from the employer for the first 6 months of illness or Short Term Lower Rate Incapacity Benefit where there is no employer to pay. After 6 months Incapacity Benefit (IB) is then payable.

(b) For those with inadequate National Insurance contributions: Income Support (IS) for those whose income and capital is below specified limits and/or Severe Disablement Allowance (SDA) after 28 weeks of incapacity for work.

(2) Help with excess costs of disability:

(a) For those with an assessment for Industrial Injuries Disablement Benefit of $100 \%$, Constant Attendance Allowance (CAA) is available.

(b) For those not entitled to CAA, Disability Living Allowance (DLA) is available for those whose disability began before their 65th birthday and Attendance Allowance (AA) is available for those whose disability began on or after their 65th birthday.

The lung cancer clinical nurse specialist has a pivotal role in assisting patients with this process. Further, reassessment of benefit entitlement should be encouraged at regular intervals as further benefits may be applicable as the patient deteriorates or upon death.

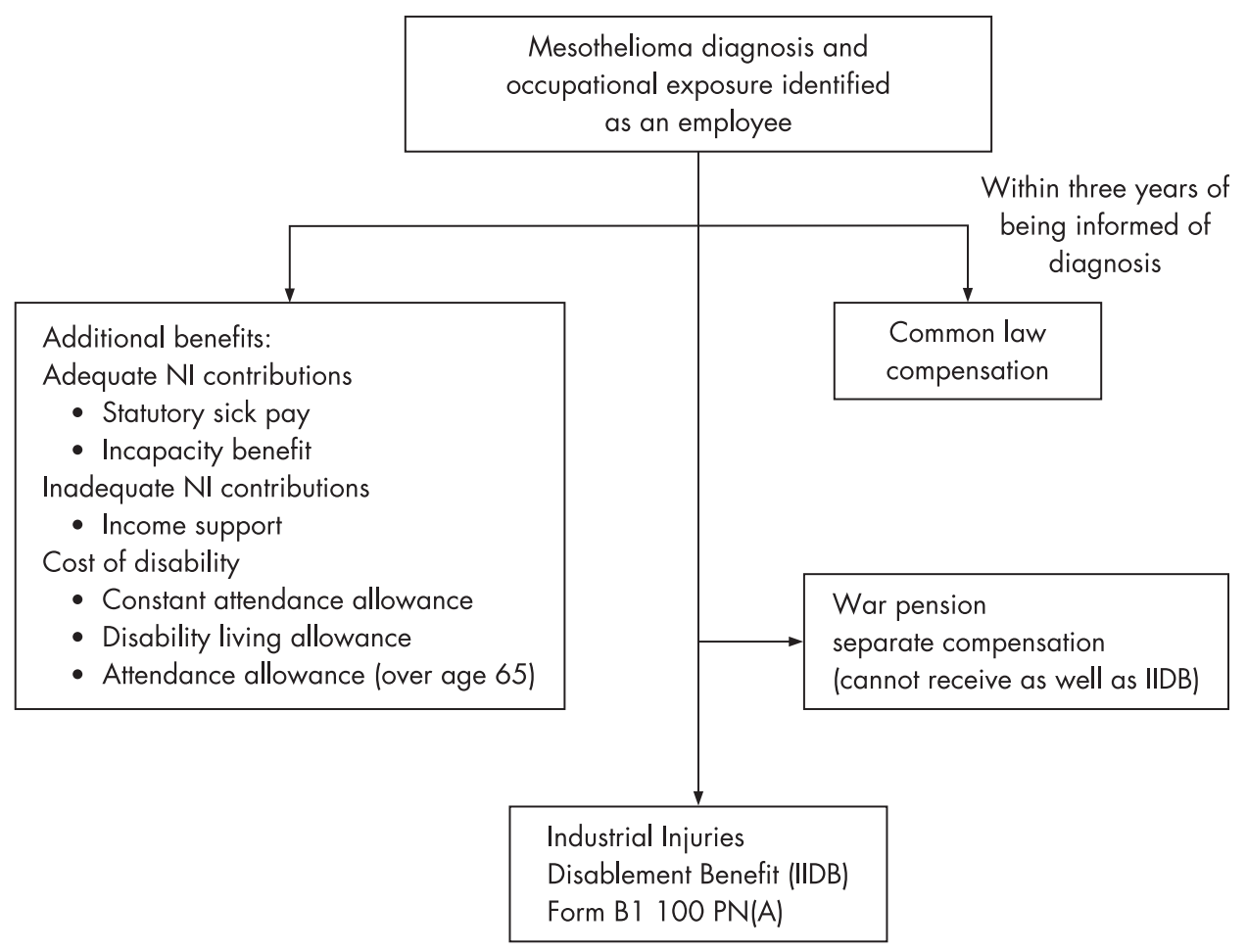

Figure 2 Summary of compensation and benefits for mesothelioma. NI, National Insurance. 


\section{Common law compensation}

Clinicians seeing any case of asbestos-related lung disease should promptly advise the patient to consider seeking legal advice. This will reduce the risk of subsequent claims for malignant mesothelioma being "statute barred" (see below). Damages may be recovered from an employer by suing them. The claimant must show that, on the balance of probabilities, his or her injuries and/or disability are due to occupational exposure to asbestos, this exposure being attributable to the employer's negligence in maintaining the standards required by common law. There may also be a breach of the employer's statutory duty to comply with specific health and safety regulations. Claims can be made against a former employer's insurer, even if the employer is no longer in business.

Proceedings for these claims must be started within 3 years of the claimant's "date of knowledge" of any injury caused by asbestos exposure. A claim brought after the expiry of 3 years is generally "statute barred" and it may not be possible to pursue it in the courts. The "date of knowledge" is based on when the claimant first becomes aware:

(a) that the injury is significant;

(b) that the injury is attributable in whole or in part to the act/ omission alleged to constitute the negligence or breach of duty; and

(c) of the identity of the defendant.

The date of knowledge is not necessarily the first time a potential claimant is examined by a doctor. The courts have the discretion to extend the 3 year time limit, but the claimant will have to persuade the court to do so.

The Compensation Act 2006 ensures that sufferers can receive full compensation from any of their employers/insurers where asbestos exposure has occurred.

If a patient is awarded damages, the final sum is based on a combination of:

- compensation for pain and suffering (and interest on that);

- loss of earnings (and interest on that);

- care costs;

- other expenses (eg, modifying the home);

- compensation for bereavement.

\section{Compensaton under the Pneumoconiosis etc (Workers' Compensation) Act 1979}

For those in whom neither an employer nor an insurer can be identified, a claim can be made to the Department of Works and Pensions under the Pneumoconiosis etc (Workers' Compensation) Act 1979. The purpose of this scheme is to provide lump sum payments to or in respect of certain persons who are, or were immediately before they died, disabled by pneumoconiosis, byssinosis or diffuse mesothelioma. Eligibility for an award depends on the following criteria being fulfilled:

(a) Industrial Injuries Disablement Benefit (IIDB) is payable to the claimant in respect of the disease;

(b) every relevant employer of his has ceased to carry on business; and

(c) the claimant has not "brought any action, or uncompromised any claim, for damages in respect of the disablement".

This last criterion means that, if the claimant has already begun a damages claim against the employer and has either settled that claim or that claim ended because the evidence against the employer was weak, then he will not be eligible for a payment under the scheme of this Act. The lump sum payable is derived from tables which are dependent upon age and the percentage disability of the IIDB, which should be $100 \%$ in the case of mesothelioma.

A summary of the compensation and benefits for mesothelioma is shown in fig 2 .

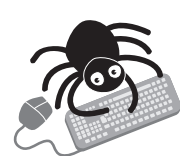

Appendices 2 (Staging systems) and 3 (Sources of information and help available for patients and carers, and advice on benefits and compensation) are available online at http://thorax.bmj.com/ supplemental

\section{REFERENCES}

1 British Thoracic Society Standards of Care Committee. Statement on malignant mesothelioma in the United Kingdom. Thorax 2001;56:250-65.

2 Department of Health. Mesothelioma Service Framework. London: Department of Health Lung Cancer and Mesothelioma Advisory Group, 2007.

3 McElvenny DM, Darnton AJ, Price MJ, et al. Mesothelioma mortality in Great Britain from 1968 to 2001. Occup Med (Lond) 2005;55:79-87.

4 Hodgson JT, McElvenny DM, Darnton AJ, et al. The expected burden of mesothelioma mortality in Great Britain from 2002 to 2050. Br J Cancer 2005;92:587-93.

5 Yates DH, Corrin B, Stidolph PN, et al. Malignant mesothelioma in south east England: clinicopathological experience of 272 cases [correction appears in Thorax 1997;52:1018]. Thorax 1997;52:507-12.

6 Howel D, Arblaster L, Swinburne L, et al. Routes of asbestos exposure and the development of mesothelioma in an English region. Occup Environ Med 1997;54:403-9.

7 Goldberg M, Imbernon E, Rolland P, et al. The French National Mesothelioma Surveillance Program. Occup Environ Med 2006;63:390-5.

8 Albin M, Magnani C, Krstev S, et al. Asbestos and cancer: an overview of current trends in Europe. Environ Health Perspect 1999;107(Suppl 2):289-98.

9 McDonald JC, McDonald AD. Mesothelioma: is there a background? In: Bignon J, Jaurand M-C, eds. The mesothelial cell and mesothelioma. New York: Marcel Dekker, 1994:chapter 3.

10 Institute of Medicine. Stratton K, Almario DA, McCormick MC, eds Immunization safety review: SV4O contamination of polio vaccine and cancer Washington, DC: National Academy of Sciences, 2002.

11 Lopes-Rios F, Illei PB, Rusch V, et al. Evidence against a role for SV40 infection in human mesothelioma and high risk of false positive PCR results owing to presence of SV 40 sequences in common laboratory plasmids. Lancet 2004;364:1159-66.

12 Manfredi JJ, Dong J, Liu W-j, et al. Evidence against a role for SV40 in human mesothelioma. Cancer Res 2005;65:2602-9.

13 Lanphear BP, Buncher CR. Latent period for malignant mesothelioma of occupational origin. J Occup Med 1992;34:718-21.

14 Hodgson JT, Darnton A. The quantitative risks of mesothelioma and lung cancer in relation to asbestos exposure. Ann Occup Hyg 2000;44:565-601.

15 Berman DW, Crump K. Technical support document for a protocol to assess asbestos-related risk, Draft prepared for US Department of Transportation and US Environmental Protection Agency, 2004.

16 MRC Institute for Environment and Health. Fibrous materials in the environment. Leicester: MRC Institute for Environment and Health, 1997.

17 Anon. Control of Asbestos Regulations 2006. Statutory Instrument 2006 No. 2739

18 Elmes PC, Simpson MJC. The clinical aspects of mesothelioma. Q J Med 1976;45:427-49.

19 Hillderdahl G. Malignant mesothelioma: a review of 4710 published cases. $\mathrm{Br} J$ Dis Chest 1983;77:321-43.

20 McGavin CR, Hughes PD. Finger clubbing in malignant mesothelioma and benign asbestos pleural disease. Respir Med 1998;92:691-2.

21 Ribak J, Selikoff JJ. Survival of asbestos insulation workers with mesothelioma $\mathrm{Br} J$ Ind Med 1992:49:732-5.

22 Van Gelder T, Damhuis RA, Hoogstedon HC. Prognostic factors and survival in malignant pleural mesothelioma. Eur Respir J 1994;7:1035-8.

23 Law MR, Hodgson ME, Heard BE. Malignant mesothelioma of the pleura: relation between histological type and clinical behaviour. Thorax 1982;37:810-5.

24 British Thoracic Society. BTS guidelines for the management of pleural disease. Thorax 2003;58(Suppl II):ii 1-59.

25 Maskell N, Gleeson FV, Davies RJ, et al. Standard pleural biopsy vs CT guided cutting needle biopsy for diagnosis of malignant disease in pleural effusions: a randomised controlled trial. Lancet 2003;361:1326-30.

26 Herth F. Diagnosis and staging of mesothelioma transthoracic ultrasound. Lung Cancer 2000;45(Suppl 1):S63-7.

27 Leung AN, Muller NL, Miller RR. CT in differential diagnosis of diffuse pleural disease. AJR 1990;154:487-92.

28 Metintas M, Ucgun I, Elbek O, et al. Computed tomography features in malignant pleural mesothelioma and other commonly seen pleural diseases. Eur J Radiol 2002;41:1-9. 
29 Knuuttila A, Kivisaari L, Kivisaari A, et al. Evaluation of pleural disease using MR and $C T$ with special reference to malignant pleural mesothelioma. Acta Radiol 2001;42:502-7.

30 Heelan RT. CT and MR imaging in the evaluation of pleural masses. Chest Surg Clin North Am 1994;3:431-50.

31 Stewart D, Waller D, Edwards J, et al. Is there a role for pre-operative contrastenhanced magnetic resonance imaging for radical surgery in malignant pleural mesothelioma? Eur J Cardiothorac Surg 2003;24:1019-24.

32 Duysinx B, Nguyen D, Louis R, et al. Evaluation of pleural disease with 18fluorodeoxyglucose positron emission tomography imaging. Chest 2004; 125:489-93.

33 Kramer H, Pieterman RM, Slebos D-J, et al. PET for the evaluation of pleural thickening observed on CT. J Nucl Med 2004;45:995-8.

34 Kwek BH, Aquino SL, Fischman AJ. Fluorodeoxyglucose positron emission tomography and CT after talc pleurodesis. Chest 2004;125:2356-60.

35 Benard F, Sterman D, Smith RJ, et al. Metabolic imaging of malignant pleural mesothelioma with fluorodeoxyglucose positron emission tomography. Chest $1998 ; 114: 713-22$.

36 Rusch VW. A proposed new international TNM staging system for malignant pleural mesothelioma: from the International Mesothelioma Interest Group. Chest 1995; 108: 1122-8.

37 Heelan RT, Rusch VW, Begg CB, et al. Staging of malignant pleural mesothelioma: comparison of CT and MR imaging. Am J Roentgenol 1999; 172:1039-46.

38 Patz EF, Shaffer K, Piwnica-Worms DR, et al. Malignant pleural mesothelioma: value of $\mathrm{CT}$ and MR imaging in predicting resectability. Am J Roentgenol 1992;159:961-6.

39 Flores RM, Akhurst T, Gonen M, et al. Positron emission tomography defines metastatic disease but not locoregional disease in patients with malignant pleural mesothelioma. J Thorac Cardiovasc Surg 2003;126:11-16.

40 Carretta A, Landoni C, Melloni G, et al. 18-FDG positron emission tomography in the evaluation of malignant pleural diseases: a pilot study. Eur J Cardiothorac Surg 2002;17:377-83

41 World Health Organisation. WHO handbook for reporting results of cancer treatment, Offset Publication No 48. Geneva: World Health Organisation, 1979.

42 Therasse P, Arbuck SG, Eisenhaver EA, et al. New guidelines to evaluate the response to treatment in solid tumours. J Natl Cancer Inst 2000;92:205-16.

43 Van Klaveren RJ, Aerts JGJV, De Bruin H, et al. Inadequacy of the RECIST criteria for response evaluation in patients with malignant pleural mesothelioma. Lung Cancer 2004;43:63-9

44 Byrne MJ, Nowak AK. Modified RECIST criteria for assessment of response in malignant pleural mesothelioma. Ann Oncol 2004;15:257-60.

45 Armato SG 3rd, Oxnard GR, MacMahon H, et al. Measurement of mesothelioma on thoracic CT scans: a comparison of manual and computerassisted techniques. Med Phys 2004;31:1105-15.

46 Whitaker $\mathbf{D}$. The cytology of malignant mesothelioma: invited review. Cytopathology 2000;11:139-51.

47 Henderson DW, Shilkin KB, Whitaker D. Reactive mesothelial hyperplasia vs mesothelioma, including mesothelioma in situ: a brief review. Am J Clin Pathol 1998; 110:397-404.

48 Travis WD, Brambilla E, Muller-Hermelink HK, et al. Tumours of the lung, pleura, thymus and heart. Lyon: IARC Press (distributed by WHO Press), 2004.

49 Adams RF, Gray W, Davies RJO, et al. Percutaneous image-guided cutting needle biopsy of the pleura in the diagnosis of malignant mesothelioma. Chest 2001;120:1798-802.

50 Metinas M, Ozdemir N, Isikoy S, et al. CT-guided pleural needle biopsy in the diagnosis of malignant mesothelioma. J Comput Assist Tomogr 1995; 19:370-4

51 Pistolesi M, Rusthoven J. Malignant pleural mesothelioma; update, current management and newer therapeutic strategies. Chest 2004;126:1318-29.

52 US-Canadian Mesothelioma Reference Panel. The separation of benign and malignant mesothelial proliferations. Am J Surg Pathol 2000;24:1 183-200.

53 King JE, Thatcher N, Pickering CAC, et al. Sensitivity and specificity of immunohistochemical markers used in the diagnosis of epithelioid mesothelioma: a detailed systematic analysis using published data Histopathology 2006;48:223-32.

54 Ordonez NG. The immunohistochemical diagnosis of mesothelioma. A comparative study of epithelioid mesothelioma and lung adenocarcinoma. Am J Surg Pathol 2003;27:1031-51.

55 Attanoos RL, Griffin A, Gibbs AR. The use of immunohistochemistry in distinguishing reactive from neoplastic mesothelium. A novel use for desmin and comparative evaluation with epithelial membrane antigen, p53, platelet-derived growth factor, P-glycoprotein and Bcl-2. Histopathology 2003;43:231-8.

56 King JE, Hasleton PS. Immunohistochemistry and the diagnosis of malignant mesothelioma. Histopathology 2001;38:471-6.

57 Galateau-Salle F, Vignaud JM, et al. Well-differentiated papillary mesothelioma of the pleura: a series of 24 cases. Am J Surg Pathol 2004;28:534-40.

58 Allen TC, Cagle PT, et al. Localized malignant mesothelioma. Am J Surg Pathol 2005;29:866-73.

59 Pass HI, Lott D, Lonardo F, et al. Asbestos exposure, pleural mesothelioma, and serum osteopontin levels. N Engl J Med 2005;353:1564-73.

60 Robinson BWS, Creaney J, Lake R, et al. Mesothelin-family proteins and diagnosis of mesothelioma. Lancet 2003;362:1612-6.

61 Schepereel A, Grigoriou B, Conti M, et al. Soluble mesothelin-related peptides in the diagnosis of malignant mesothelioma. Am J Respir Crit Care Med 2006;173:1155-60.
62 National Institute for Clinical Excellence (NICE). Improving supportive and palliative care for adults with cancer. London: NICE, 2004.

63 Butchart EG, Ashcroft T, Barnsley WC, et al. Pleuropneumonectomy in the management of diffuse malignant mesothelioma of the pleura. Experience with 29 patients. Thorax 1976;31:15-24.

64 Treasure T, Sedrakyam A. Pleural mesothelioma: little evidence, still time to do trials. Lancet 2004;364:1183-5.

65 Opitz I, Kestenholz P, Lardinois D, et al. Incidence and management of complications after neoadjuvant chemotherapy followed by extrapleural pneumonectomy for malignant pleural mesothelioma. Eur J Cardiothorac Surg 2006;29:579-84

66 Weder W, Kestenholz P, Taverna C, et al. Neoadjuvant chemotherapy followed by extrapleural pneumonectomy in malignant pleural mesothelioma. J Clin Oncol 2004;22:3451-7

67 Sugarbaker DJ, Jaklitsch MT, Bueno R, et al. Prevention, early detection, and management of complications after 328 consecutive extrapleural pneumonectomies. J Thorac Cardiovasc Surg 2004; 128:138-46.

68 Sugarbaker DJ, Flores RM, Jaklitsch MT, et al. Resection margins, extrapleura nodal status, and cell type determine postoperative long-term survival in trimodality therapy of malignant pleural mesothelioma: results in 183 patients J Thorac Cardiovasc Surg 1999;1 17:54-63

69 Maggi G, Casadio C, Cianci R, et al. Trimodality management of malignant pleural mesothelioma. Eur J Cardiothorac Surg 2001;19:346-50.

70 Rusch VW, Rosenzweig K, Venkatraman E, et al. A phase II trial of surgical resection and adjuvant high-dose hemithoracic radiation for malignant pleural mesothelioma. J Thorac Cardiovasc Surg 2001;122:788-95.

71 Aziz T, Jilaihawi A, Prakash D. The management of malignant pleural mesothelioma; single centre experience in 10 years. Eur J Cardiothorac Surg 2002;22:298-305

72 Lee $\Pi$, Everett DL, Shu HK, et al. Radical pleurectomy/decortication and intraoperative radiotherapy followed by conformal radiation with or without chemotherapy for malignant pleural mesothelioma. J Thorac Cardiovasc Surg 2002; 124:1183-9.

73 Ahamad A, Stevens CW, Smythe WR, et al. Promising early local control of malignant pleural mesothelioma following postoperative intensity modulated radiotherapy (IMRT) to the chest. Cancer J 2003;9:476-84.

74 Stewart DJ, Martin-Ucar A, Pilling JE, et al. The effect of extent of local resection on patterns of disease progression in malignant pleural mesothelioma. Ann Thorac Surg 2004;78:245-52.

75 Maziak DE, Gagliardi A, Haynes AE, et al. Surgical management of malignant pleural mesothelioma: a systematic review and evidence summary. Lung Cancer 2005;48:157-69.

76 British Thoracic Society. BTS guidelines on the selection of patients with lung cancer for surgery. Thorax 2001;56:89-108.

77 Edwards JG, Stewart DJ, Martin-Ucar A, et al. The pattern of lymph node involvement influences outcome after extrapleural pneumonectomy for malignant mesothelioma. J Thorac Cardiovasc Surg 2006;131:981-7.

78 Truong MT, Marom EM, Erasmus JJ. Preoperative evaluation of patients with malignant pleural mesothelioma: role of integrated CT-PET imaging. J Thorac Imaging 2006;21:146-53

79 Grossebner MW, Arifi AA, Goddard M, et al. Mesothelioma: VATS biopsy and lung mobilization improves diagnosis and palliation. Eur J Cardiothorac Surg 1999;16:619-23.

80 Soysal O, Karaoglanoglu N, Demiracan S, et al. Pleurectomy/decortication for palliation in malignant pleural mesothelioma: results of surgery. Eur J Cardiothorac Surg 1997;11:210-3.

81 Boutin C. Prevention of malignant seeding after invasive diagnostic procedures in patients with pleural mesothelioma. A randomised trial of local radiotherapy Chest 1995;108:754-8.

82 Waller DA, Morritt GN, Forty J. Video-assisted thoracoscopic pleurectomy in the management of malignant pleural effusion. Chest 1995;107:1454-6.

83 Rodriquez-Panadero F. Thoracoscopy: general overview and place in the diagnosis and management of pleural infection. Eur Respir J 2006;28:409-22.

84 Loddenkemper R. Thoracoscopy: state of the art. Eur Respir J 1998;1 1:213-21.

85 Arapis K. Thoracoscopic palliative treatment of malignant pleural effusions: results in 273 patients. Surg Endosc 2006;20:919-23.

86 Light RW. The undiagnosed pleural effusion. Clin Chest Med 2006;27:309-19.

87 Tan C, Sedrakyan A, Brown J, et al. The evidence on the effectiveness of management for malignant pleural effusion: a systematic review. Eur J Cardiothorac Surg 2006;29:829-38.

88 Shaw P, Agarwal R. Pleurodesis for malignant pleural effusions. In: Cochrane Library, Issue 1. Oxford: Update Publications, 2004.

89 British Thoracic Society. BTS guidelines for the management of malignant pleural effusions. Thorax 2003;58(Suppl II):ii29-38

90 Dryzer SR, Allen ML, Strange C, et al. A comparison of rotation and nonrotation in talc pleurodesis. Chest 1993;104:1763-6.

91 Mager HJ, Maesen R, Verziilbergen F, et al. Distribution of suspension during treatment of malignant pleural effusion with talc pleurodesis. Lung Cancer 2002;36:77-81.

92 Marom EM. Malignant pleural effusions: treatment with small-bore catheter thoracostomy and talc pleurodesis. Radiology 1999;210:277-81

93 Maskell RL. Pleurodesis with iodized talc for malignant effusions using pigtail catheters. Ann Pharmacother 1998;32:739-42.

94 Maskell N. The influence of talc particle size on lung and systemic inflammation after pleurodesis for malignant pleural effusion: randomised trials of small and large talc particles and tetracycline. Am J Respir Crit Care Med 2004; 170:377-82.

95 Genc $\mathbf{O}$. The long term morbidity of pleuroperitoneal shunts in the management of recurrent effusions. Eur J Cardiothorac Surg 2000;18:143-6. 
96 den Toorn LM. Management of recurrent malignant pleural effusions with a chronic indwelling pleural catheter. Lung Cancer 2005;50:123-7.

97 Tremblay A, Michaud G. Single centre experience with 250 tunnelled pleural catheter insertions for malignant effusions. Chest 2006; 129:362-8.

98 Gupta V, Mychalczak B, Krug L, et al. Hemithoracic radiation therapy after pleurectomy/decortication for malignant pleural mesothelioma. Int J Radiat Oncol Biol Phys 2005;63:1045-52.

99 Davis SR, Tan L, Ball DL. Radiotherapy in the treatment of malignant mesothelioma with special reference to its use in palliation. Austral Radiol 1994;38:212-4

100 De Graaf-Strukowska L, Van der Zee J, Van Putten W, et al. Factors influencing the outcome of radiotherapy in malignant mesothelioma of the pleura: a single institution experience with 189 patients. Int J Radiat Oncol Biol Phys 1999;43:511-6.

101 Bissett D, Macbeth FR, Cram I. The role of palliative radiotherapy in malignant mesothelioma. Clin Oncol 1991;3:315-7.

102 Yajnik S, Rosenzweig KE, Mychalczak B, et al. Hemithoracic radiation after extrapleural pneumonectomy for malignant pleural mesothelioma. Int J Radiat Oncol Biol Phys 2003;56:1319-26.

103 Ahamad A, Stevens C, Smythe WR, et al. Intensity modulated radiation therapy: a novel approach to the management of malignant pleural mesothelioma. Int J Radiat Oncol Biol Phys 2003;55:768-75.

104 Stevens C, Forster K, Zhu X, et al. Excellent local control and survival after extrapleural pneumonectomy and IMRT for mesothelioma. Proceedings of the 47th American Society for Therapeutic Radiology and Oncology (ASTRO) Meeting, abstract $\mathrm{S} 103$.

105 Bydder S, Philips M, Joseph DJ, et al. A randomised trial of single dose radiotherapy to prevent procedure tract metastasis by malignant mesothelioma. Br J Cancer 2004;91:9-10.

106 Vogelzang NJ, Rusthoven JJ, Symanowski J, et al. Phase III study of pemetrexed in combination with cisplatin vs cisplatin alone in patients with malignant pleural mesothelioma. J Clin Oncol 2003;21:2636-44.

107 Ellis P, Davies M, Evans WK, et al. Use of chemotherapy in patients with advanced malignant pleural malignant mesothelioma: a systematic review and practice guideline. J Thorac Oncol 2006;1:591-601.

108 O'Brien ME, Watkins D, Ryan C, et al. A randomised trial in malignant mesothelioma (M) of early (E) vs delayed (D) chemotherapy in systematically stable patients: the MED trial. Ann Oncol 2006;17:270-5

109 Muers MF, Rudd RM, O'Brien MER, et al. British Thoracic Society (BTS) randomised feasibility study of active symptom control with or without chemotherapy in malignant pleural mesothelioma: ISRCTN 54469112. Thorax 2004;59:144-8.

110 Middleton GW, Smith IE, O'Brien ME, et al. Good symptom relief with palliative MVP (mitomycin-C, vinblastine and cisplatin) chemotherapy in malignant mesothelioma. Ann Oncol 1998;9:269-73.

111 Andreopoulou E, Ross PJ, O'Brien MER, et al. The use of mitomycin C, vinblastine, and cisplatin chemotherapy in patients with malignant mesothelioma. Ann Oncol 2004; 15:1406-12.

112 Steele JPC, Shamash J, Evans M, et al. Phase II study of vinorelbine in patients with malignant pleural mesothelioma. J Clin Oncol 2000;18:3912-7.

113 Steele JPC, Shamash J, Gower NH, et al. Vinorelbine (Navelbine) given as a single agent for malignant pleural mesothelioma. Results from 65 patients at a single centre. Lung Cancer 2000;29(S1):18.

114 Byrne MJ, Davidson JA, Musk AW, et al. Cisplatin and gemcitabine treatment for malignant mesothelioma: a phase II study. J Clin Oncol 1999:17:25-30.

115 Nowak AK, Byrne MJ, Williamson R, et al. A multicentre phase II study of cisplatin and gemcitabine for malignant mesothelioma. Br J Cancer 2002;87:491-6.

116 van Haarst JM, Baas $\mathrm{P}$, Manegold C, et al. Multicentre phase II study of gemcitabine and cisplatin in malignant pleural mesothelioma. $\mathrm{Br} J$ Cancer 2002;86:342-5

117 Castagneto B, Zai S, Dongiovanni $\mathrm{E}$, et al. Cisplatin and gemcitabine in malignant pleural mesothelioma: a phase II study (abstract). Proc Am Soc Clin Oncol 2003;22:656.

118 Favaretto AG, Aversa SML, Paccagnella A, et al. Gemcitabine combined to carboplatin in malignant pleural mesothelioma: a multicentric phase II study. Lung Cancer 2003;41(S2):218

119 Fennell DA, Steele JPC, Shamash J, et al. A Phase II study of irinotecan, cisplatin, and mitomycin C (IPM) in malignant pleural mesothelioma. Lung Cancer 2003;41(S2):221.

120 Hazarika M, White RM, Booth BP, et al. Pemetrexed in malignant pleural mesothelioma. Report from the Food and Drug Administration. Clin Cancer Res 2005; 11:982-92.

121 Gralla RJ, Hollen PJ, Liepa AM, et al. Improving quality of life in patients with malignant pleural mesothelioma: results of the randomised pemetrexed + cisplatin trial using the LCSS-meso instrument (abstract). Proc Am Soc Clin Oncol 2003;22:621

122 Manegold C, Symanowski J, Gatzmeier U, et al. Second line (post study) chemotherapy received by patients treated in the phase III trial of pemetrexed plus cisplatin compared with cisplatin alone in malignant pleural mesothelioma Ann Oncol 2005;16:923-7.

123 Hughes A, Calvert P, Azzabi A, et al. Phase I clinical and pharmacokinetic study of pemetrexed and carboplatin in patients with malignant pleural mesothelioma. J Clin Oncol 2002;20:3533-44.

124 Ceresoli GL, Zucali PA, Favaretto AG, et al. Phase II study of pemetrexed plus carboplatin in malignant pleural mesothelioma. J Clin Oncol 2006;24:1443-8.

125 Van Meerbeeck JP, Gaafar R, Manegold C, et al. A randomized phase III study of cisplatin with or without raltitrexed in patients with malignant pleural mesothelioma: an intergroup study of the European Organisation for Research and Treatment of Cancer Lung Cancer Group and the National Cancer Institute of Canada. J Clin Oncol 2005;23:6881-9.

126 Kindler HL, Karrison T, Lu C, et al. A multicenter, double-blind, placebocontrolled randomized phase II trial of gemcitabine/cisplatin (GC) plus bevacizumab (B) or placebo in patients (pts) with malignant mesothelioma (MM). Proc Ann Meet Am Soc Clin Oncol 2005;23:7019.

127 Mikulski SM, Costanzi JJ, Vogelzang NJ, et al. Phase II trial of a single weekly intravenous dose of ranpirnase in patients with unresectable malignant mesothelioma. J Clin Oncol 2002;20:274-81.

128 Riganti C, Orecchia S, Pescarmona G, et al. Statins revert doxorubicin resistance via nitric oxide in malignant mesothelioma. Int J Cancer 2006; 119:17-27.

129 Szlosarek PW, Klabatsa A, Pallaska A, et al. In vivo loss of expression of argininosuccinate synthetase in malignant pleural mesothelioma is a biomarker for susceptibility to arginine depletion. Clin Cancer Res 2006;12:7126-31.

130 Robinson BW, Musk AW, Lake RA. Malignant mesothelioma. Lancet 2005:366:397-408

131 van der Most RG, Robinson BW, Nelson DJ. Gene therapy for malignant mesothelioma: beyond the infant years. Cancer Gene Ther 2006;13:897-904.

132 Rodrigues E, Baas P, Friedberg JS. Innovative therapies: photodynamic therapy. Thorac Surg Clin 2004; 14:557-66.

133 Doyle D, Hanks DWC, Cherny NI, et al, eds. Oxford textbook of palliative medicine. 3rd edn. Oxford: Oxford University Press, 2004.

134 Twycross R. Introducing palliative care, 4th edn. UK: Radcliffe Medical Press, 2003

135 Department of Health. Integrating lung cancer nursing; a good practice guide, NHS Modernisation Agency. London: Department of Health, 2004.

136 Amesbury B, O'Riordan J, Dolin S. The use of interpleural analgesia using bupivacaine for pain relief in advanced cancer. Palliative Med 1999;13:153-8.

137 Jackson MB, Pounder D, Price C et al. Percutaneous cervical cordotomy for the control of pain in patients with pleural mesothelioma. Thorax 1999;54:238-41.

138 Bredin M, Corner J, Krishnasamy M, et al. Multicentre randomised controlled trial of nursing intervention for breathlessness in patients with lung cancer. $B M J$ 1999:318:901-4.

\section{APPENDIX 1: MEMBERSHIP OF THE BTS WORKING PARTY}

Professor M G Britton, Consultant Chest Physician, St Peter's Hospital, Chertsey, Surrey; Ms L Darlison, Consultant Nurse, Glenfield Hospital, Leicester; Dr J Entwisle, Consultant Radiologist, Glenfield Hospital, Leicester; Dr M A Greenstone, Consultant Physician, Castle Hill Hospital, Cottingham, Hull; Dr M Hetzel, Consultant Physician, Bristol Royal Infirmary, Bristol; Dr C Higgs, Medical Director, Dorothy House Hospice, Winsley, Bradford-on-Avon, Wiltshire; Dr N Maskell, Consultant Physician, Bristol; Dr M F Muers, Consultant Physician, The General Infirmary, Leeds; Dr R Rudd, Consultant Physician, London Chest Hospital, London; Professor T Treasure, Consultant Thoracic Surgeon, Guys Hospital, London; Dr J Wiggins (Chairman and Editor of Statement), Consultant Physician, Wexham Park Hospital, Wexham, Slough, Berkshire.

Additional contributions were obtained from Dr A Darnton, Epidemiology and Medical Statistics Unit, Health and Safety Executive, Magdalen House, Stanley Precinct, Bootle; Dr M Snee, Consultant Medical Oncologist, Leeds; Dr M Sheaff, Consultant Histopathologist, St Bartholomew's Hospital, London; Ms C Tan, Specialist Registrar, Guys Hospital, London; Dr D R Baldwin on behalf of the BTS Lung Cancer and Mesothelioma Specialist Advisory Group. 